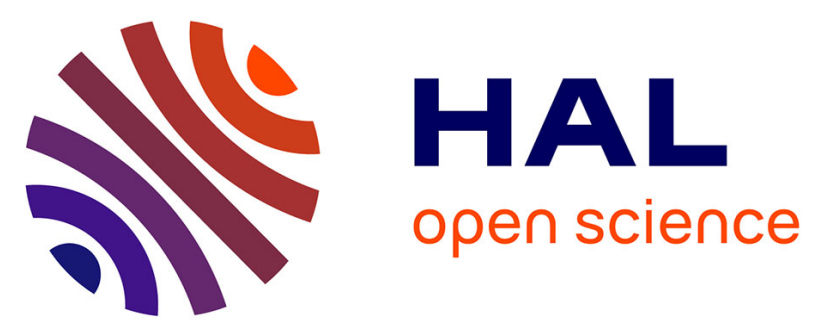

\title{
Parallel Developments and Formal Collaboration between European Atmospheric Profiling Observatories and the U.S. ARM Research Program
}

M. Haeffelin, S. Crewell, A. J. Illingworth, G. Pappalardo, H. Russchenberg, Marjolaine Chiriaco, K. Ebell, R. J. Hogan, F. Madonna

\section{To cite this version:}

M. Haeffelin, S. Crewell, A. J. Illingworth, G. Pappalardo, H. Russchenberg, et al.. Parallel Developments and Formal Collaboration between European Atmospheric Profiling Observatories and the U.S. ARM Research Program. Meteorological Monographs- American Meteorological Society, 2016, 57, pp.29. 10.1175/AMSMONOGRAPHS-D-15-0045.1 . insu-01369370

\section{HAL Id: insu-01369370 \\ https://hal-insu.archives-ouvertes.fr/insu-01369370}

Submitted on 21 Sep 2016

HAL is a multi-disciplinary open access archive for the deposit and dissemination of scientific research documents, whether they are published or not. The documents may come from teaching and research institutions in France or abroad, or from public or private research centers.
L'archive ouverte pluridisciplinaire HAL, est destinée au dépôt et à la diffusion de documents scientifiques de niveau recherche, publiés ou non, émanant des établissements d'enseignement et de recherche français ou étrangers, des laboratoires publics ou privés. 


\title{
Chapter 29
}

\section{Parallel Developments and Formal Collaboration between European Atmospheric Profiling Observatories and the U.S. ARM Research Program}

\author{
M. Haeffelin, ${ }^{*}$ S. Crewell,${ }^{+}$A. J. Illingworth, ${ }^{\#}$ G. Pappalardo,${ }^{@}$ H. Russchenberg, ${ }^{\&}$ \\ M. ChIRIACO, ${ }^{* *}$ K. EBEll, ${ }^{+}$R. J. HOGAN, ${ }^{\#}$ AND F. MADONnA ${ }^{@}$ \\ * L'Institut Pierre-Simon Laplace, Centre National de la Recherche Scientifique, Palaiseau, France \\ ${ }^{+}$Institute for Geophysics and Meteorology, University of Cologne, Cologne, Germany \\ \# Department of Meteorology, University of Reading, Reading, United Kingdom \\ ${ }^{\circledR}$ Consiglio Nazionale delle Ricerche-Istituto di Metodologie per l'Analisi Ambientale, Potenza, Italy \\ \& Department of Geoscience and Remote Sensing, Delft University of Technology, Delft, Netherlands \\ ** Laboratoire Atmosphère, Milieu, Observations Spatiales, Université Versailles Saint Quentin en Yvelines, \\ Guyancourt, France
}

\section{Introduction}

The climate research community aims to better characterize climate forcings such as aerosols, reactive gases, and greenhouse gases, and to better understand the responses of the climate system to these forcings. Such investigations rely in part on monitoring, studying, and understanding essential climate variables such as temperature, water vapor, clouds, radiation, and perturbations of aerosols and reactive gases. According to Dufresne and Bony (2008), the parameters that play a predominant role in radiative feedbacks of the climate system are atmospheric humidity, adiabatic thermal gradients, clouds, and surface albedo. Interactions between humidity, clouds, aerosols, and radiation make climate predictions more complex.

The climate research community has long recognized the link between climate prediction uncertainty and atmospheric process complexity. For more than 20 years, it has demonstrated the necessity to perform collocated long-term observations of thermodynamic parameters (temperature, humidity, wind) and atmospheric constituents (gases, aerosols, clouds) distributed along the entire atmospheric column (surface to stratosphere) and associated radiative components.

As a result, the U.S. Department of Energy (DOE) launched the Atmospheric Radiation Measurement (ARM)

Corresponding author address: Martial Haeffelin, L'Institut PierreSimon Laplace, Palaiseau, 91128, France.

E-mail: martial.haeffelin@ipsl.polytechnique.fr
Program in the 1990s (Ackerman and Stokes 2003; Stokes 2016, chapter 2). Four atmospheric profiling observation facilities were developed to gather in situ and remote sensing instruments to monitor physical processes in the atmospheric column. A large research community of observation experts and climate modelers was funded to exploit the observation data. Similar atmospheric profiling observation facilities associated with large scientific communities emerged in Europe at the end of the 1990s. Several European initiatives were triggered or encouraged through bilateral collaborations between U.S. and European Union (EU) scientists or through participation of EU scientists in ARM projects (e.g., Cabauw observatory in the Netherlands; Palaiseau observatory in France; Jülich observatory in Germany).

Atmospheric profiling observatories provide scientists with the most resolved description of the atmospheric column. In Europe, as in the United States, these observatories have been collecting data every minute daily for more than a decade, allowing links to be established between processes occurring at diurnal or finer temporal scales and phenomenon occurring at climate scales. The limitation of an atmospheric profiling observatory is that it can only document one location of the globe with its specific atmospheric properties. The aerosol distributions, meteorological anomalies, and cloud properties observed at that location are representative of a limited spatial domain. Hence, atmospheric profiling observatories are needed at many locations around the globe to cover climatically diverse areas: near coasts, in continental 
plains, mountains, and urban environments. The U.S. ARM Program was designed initially to cover three distinct climatic regions (Cress and Sisterson 2016, chapter 5): the Arctic (Alaska), midlatitudes [U.S. southern Great Plains (SGP)], and the tropics [tropical western Pacific (TWP) Ocean]. Atmospheric profiling observatories in Europe were developed primarily over the European continent, extending from locations around the Mediterranean Basin to the Arctic, and including coastal, continental, urban, and mountain sites.

The European Commission established several funding mechanisms to develop collaborations between researchers in Europe, to promote development of harmonized research infrastructures, and to reduce fragmentation in European research investments. As a result, in the past 10 years Europe was able to build an infrastructure essential to a large community of users by harmonizing aerosol, cloud, and trace gas observations across Europe.

As infrastructures, measurement techniques, data interpretation algorithms, and scientific expertise developed on both sides of the Atlantic, scientists became interested in the added benefits of collaboration and cross-fertilization between the U.S. ARM Program and EU atmospheric profiling research observatories. To expand investigations beyond existing atmospheric observatories, U.S. ARM scientists and ARM Mobile Facility (AMF) infrastructures participated in field experiments initiated by EU programs. EU and U.S. ARM scientists developed collaborations to harmonize data interpretation algorithms and to exploit jointly U.S. and EU observation datasets. Further development of formal collaboration between U.S. ARM and EU programs would enhance the ability of scientists worldwide to take on science challenges about climate change.

This chapter presents several European atmospheric profiling research observatories, development of European networking, and the current European research infrastructure (section 2). Section 3 presents EU program initiatives of interest for future collaboration with the ARM Program. Section 4 highlights collaborations that were developed subsequently between the U.S. ARM Program and its European counterparts. In section 5, we present an outlook toward future U.S.-EU collaborations around climate change challenges and observations.

\section{European atmospheric profiling research observatories}

Atmospheric profiling capabilities using active and passive remote sensing were developed as independent national initiatives in several European countries in the 1990s. Meteorological services and research institutes gathered several remote sensing systems, collocated them, and started to develop capacities to perform continuous measurements of atmospheric profiles and to store data for scientific research (section 2a). Through different initiatives of the European commission, several projects emerged in the early 2000s to coordinate atmospheric remote sensing activities across multiple European countries (section 2b). At the end of the 2000s, these coordination efforts were taken one step further to create a European research infrastructure initiative dedicated to a Europewide coordination of atmospheric profiling of aerosols, clouds, and trace gases for scientific research (section 2c).

\section{a. National atmospheric profiling research observatories}

Atmospheric profiling research observatories (APRO) with remote sensing capabilities were developed in Europe toward the end of the 1990s, a few years after the start of the U.S. ARM Program. Some APROs were developed by National Hydrological and Meteorological Services and their partners around existing meteorological facilities. Weather observations started in 1905 at the Meteorologisches Observatorium Lindenberg, now called the Richard Assmann Observatory, which became an atmospheric profiling observatory with remote sensing capabilities operated by the German Weather Service (DWD) in the mid-1990s. Similarly, the Royal Netherlands Meteorological Office (KNMI) founded a meteorological observatory in the early 1970s, which was upgraded in the early 2000s with many remote sensing instruments to become one of the more prominent European facilities for atmospheric research. Another example is the Payerne aerological station of the Swiss Meteorological Institute located in the western part of the Swiss midland.

Other observatories were developed by national research communities by bringing together atmospheric and climate scientists, who were experts in different remote sensing techniques. Some national research communities were connected to the ARM research community through participations in ARM projects or through bilateral collaborations with ARM scientists. This was the case of the SIRTA Observatory near Paris, France, which started from the initiative of a scientist in the 1990s. The development of the site was boosted in the early 2000s through collaboration with ARM scientists and participation in EU networks. Fifteen years later it has become a prominent European facility operating more than 100 sensors from 10 different institutes. In 1975, the National University of Ireland (Galway) established the Atmospheric Research station at Mace Head on the west coast of Ireland. The major observatory has been 


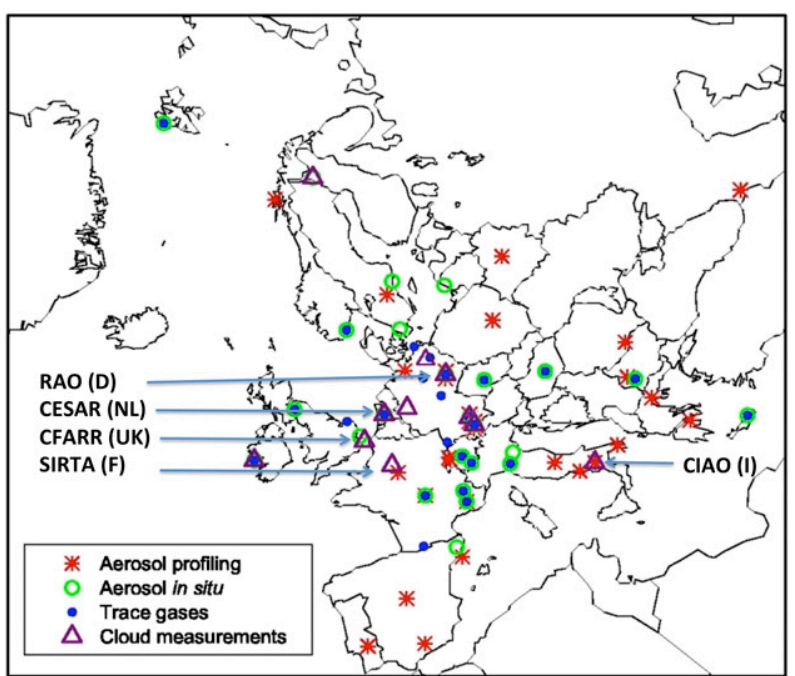

FIG. 29-1. Map of aerosol, cloud, and trace gas profiling and in situ measurement infrastructures in Europe, extending from the Mediterranean Basin to the polar regions (in 2011). Blue arrows indicate the geographical locations of the five European atmospheric observatories presented in section 2a.

used as a background baseline research station for over 50 years. (Aerosol measurements started in 1958 at a location nearby.)

Figure 29-1 shows the geographical distribution of atmospheric observatories in Europe dedicated to aerosol, cloud, and trace gas monitoring. Figure 29-1 highlights five prominent European atmospheric research observatories that contribute to many international networks, like the Baseline Surface Radiation Network (BSRN); the European Aerosol Research Lidar Network (EARLINET); Cloudnet; Aerosols, Clouds, and Trace
Gases Research Infrastructure (ACTRIS) network; and Global Climate Observing System Upper-Air Reference Network (GRUAN). Their facilities, instruments, developments, and activities are presented in the following five subsections.

Atmospheric profiling observation activities in Europe were given a major boost in 1998 when the European Space Agency financed the 1998 Cloud Lidar and Radar Experiment (CLARE'98) field campaign. This campaign involved flying three instrumented aircraft from Germany, France, and the United Kingdom equipped with in situ sampling instruments, cloud radar, and lidars over the ground-based 94-GHz cloud radar at the Chilbolton observatory in the United Kingdom. This campaign demonstrated the ability of cloud radars and lidars to infer cloud properties leading to the selection of the joint European-Japanese Earth Clouds, Aerosol and Radiation Explorer (EarthCARE) satellite mission, which is scheduled to be launched in 2017. More recently, national meteorological and atmospheric research communities realized that activities around atmospheric profiling measurement and scientific research exploiting these measurements could be coordinated at regional or national levels, which led to construction of national networks of atmospheric profiling observatories. One example is a German network whose goal is to harmonize activities of several observatories around the High Definition Clouds and Precipitation for Climate Prediction project $\left[\mathrm{HD}(\mathrm{CP})^{2}\right]$. Another example is the French Réseau d'Observatoires pour la Surveillance de l'Eau Atmosphérique (ROSEA), a network of five observatories dedicated to atmospheric water profiling. The geographical distributions of these two national networks are shown in Fig. 29-2.
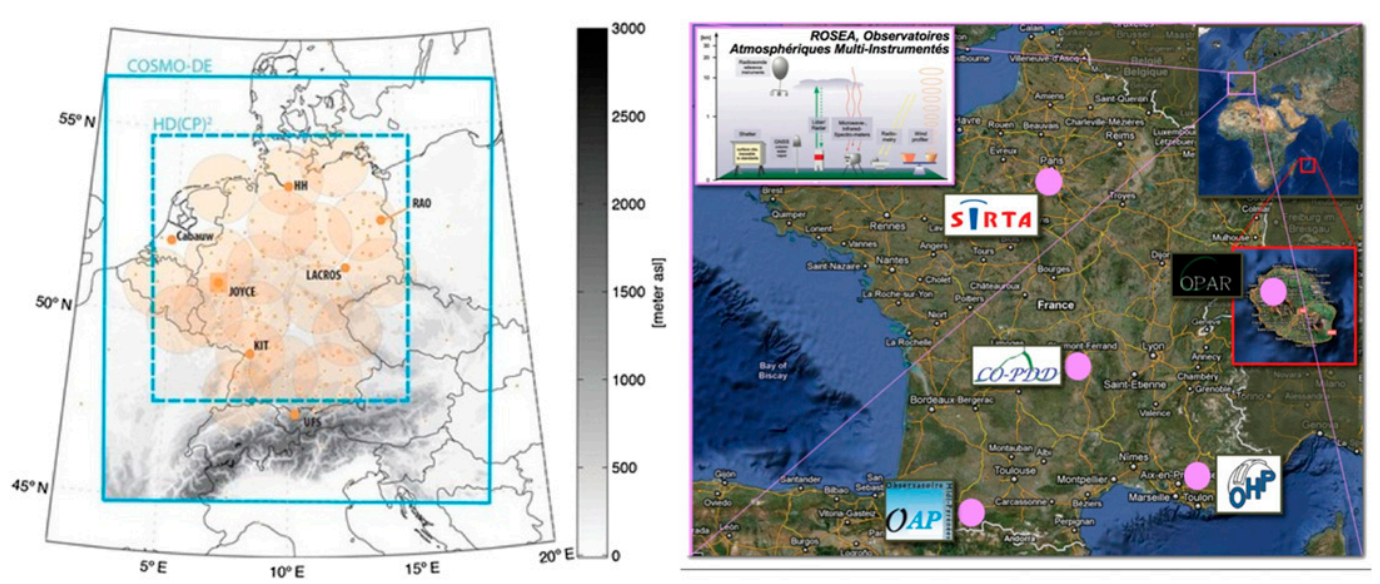

FIG. 29-2. Geographical locations of (a) German atmospheric profiling research observatories part of $\mathrm{HD}(\mathrm{CP})^{2}$ and (b) French network of observatories for atmospheric water and aerosol profiling, including four observatories in continental France and one on Réunion Island (Indian Ocean). 


\section{1) The CABAuw EXPerimental Site for ATMOSPHERIC RESEARCH}

The Cabauw Experimental Site for Atmospheric Research (CESAR) observatory is located in the western part of the Netherlands $\left(\mathrm{NL} ; 51.97^{\circ} \mathrm{N}, 4.92^{\circ} \mathrm{E}\right)$. The site is located close to the sea and to some of the major European industrial and populated areas. The site is exposed to a large variety of airmass types. In 1973, a 213-m-high meteorological mast was built at the Cabauw site for the study of the atmospheric boundary layer (ABL), land surface conditions, and the general weather situation. Also, well-kept observation fields are onsite for micrometeorological observations, including soil heat flux, soil temperatures, and various radiation measurements (including a BSRN station). Within a 40-km radius, there are four major synoptic weather stations, ensuring a permanent supporting mesoscale network. Since 2000, remote sensing observations have been performed on clouds, rain, aerosols, and radiation (see Table 29-1 and Fig. 29-3b). Since 2002 the CESAR Observatory has been a national facility with commitments from eight research institutes and universities.

The CESAR site is used for

- monitoring long-term tendencies in atmospheric changes;

- studying atmospheric and land surface processes for climate and weather modeling;

- validating spaceborne observations;

- developing and implementing new measurement techniques;

- training young scientists at postdoctoral, Ph.D., and Masters levels.

Selected research highlights are presented in Table 29-2. The observatory is also used by the industry to test new technologies, either for comparison with similar instruments or for long-term endurance tests. All data are freely available through the CESAR data portal (www. cesar-observatory.nl), which also lists all publications that report on the use of CESAR data.

\section{2) The Richard AsSMANn ObSERVATORY AND} GERMAN OBSERVATORY NETWORK

The Meteorological Observatory Lindenberg-Richard Assmann Observatory (MOL-RAO) at Lindenberg operated by the DWD was originally founded in 1905 . Since 1991, the MOL-RAO has been part of the DWD with extensive facilities. MOL-RAO serves as a regional reference station for many international programs and projects (Neisser et al. 2002). MOL-RAO $\left(52.17^{\circ} \mathrm{N}\right.$, $14.12^{\circ} \mathrm{E}$ ) is located in a rural environment dominated by farmland about $60 \mathrm{~km}$ to the southeast of Berlin (see
Fig. 29-3a and Table 29-1). The midlatitude site is characterized by moderate climate in the transition zone between maritime and continental climate. In addition to the MOL-RAO, several advanced atmospheric profiling sites have become operational in Germany (see Fig. 29-2a). The Jülich Observatory for Cloud Evolution (JOYCE; Löhnert et al. 2014), located in the westernmost part of Germany $\left(50.91^{\circ} \mathrm{N}, 6.41^{\circ} \mathrm{E}, 111 \mathrm{~m} \mathrm{MSL}\right)$, was established in 2011 to characterize boundary layer clouds in the environment in which they form and decay. The Environmental Research Station Schneefernerhaus (UFS) is a unique research station located at an elevation of $2650 \mathrm{~m}$ in the Bavarian Alps just $300 \mathrm{~m}$ below the peak of the Zugspitze mountain (Germany's highest mountain). Originally set up for atmospheric trace gas measurements, it has now turned into a multipurpose station managed as a virtual institute for altitude, environment, and climate research by the Bavarian State Ministry of the Environment. Two mobile atmospheric profiling facilities [i.e., Leipzig Aerosol and Cloud Remote Observations System (LACROS) by the Leibniz Institute for Tropospheric Research, and the Karlsruhe Institute of Technology's (KIT) KITCube] were also developed. In total, seven K-band cloud radars operate continuously, giving Germany the world's densest cloud radar network. Selected MOL-RAO and JOYCE research highlights are presented in Table 29-3.

\section{3) The Chilbolton FAcility FOR ATMOSPHERIC AND RADIO RESEARCH}

The Chilbolton observatory, located in Hampshire, United Kingdom $\left(51.14^{\circ} \mathrm{N}, 1.44^{\circ} \mathrm{W}\right)$, was opened in 1967 when the construction of the $25-\mathrm{m}$ dish was completed, and it now hosts the Chilbolton Facility for Atmospheric and Radio Research (CFARR). The S-band 3-GHz Advanced Meteorological Radar (CAMRa) installed on the big dish is the largest fully steerable meteorological radar in the world and is able to probe clouds and storms with unparalleled sensitivity and resolution. In 1980, it provided the first demonstration of improved radar estimates of rainfall by transmitting and receiving pulses alternately polarized in the horizontal and vertical (Hall et al. 1984). CFARR now comprises 20 major instruments (Fig. 29-3e), 10 of which are new since 2005, for studying clouds, rainfall, boundary layer processes, and aerosols (see Table 29-1). Many instruments operate $24-7$ including the $35-\mathrm{GHz}$ cloud radar, ceilometer, and microwave radiometer to provide continuous monitoring of the vertical structure of clouds and aerosol backscatter as part of the Cloudnet activity described in section 2b. Meteorological instruments include highresolution rain gauges and disdrometers to measure raindrop spectra. All data are archived at the British 


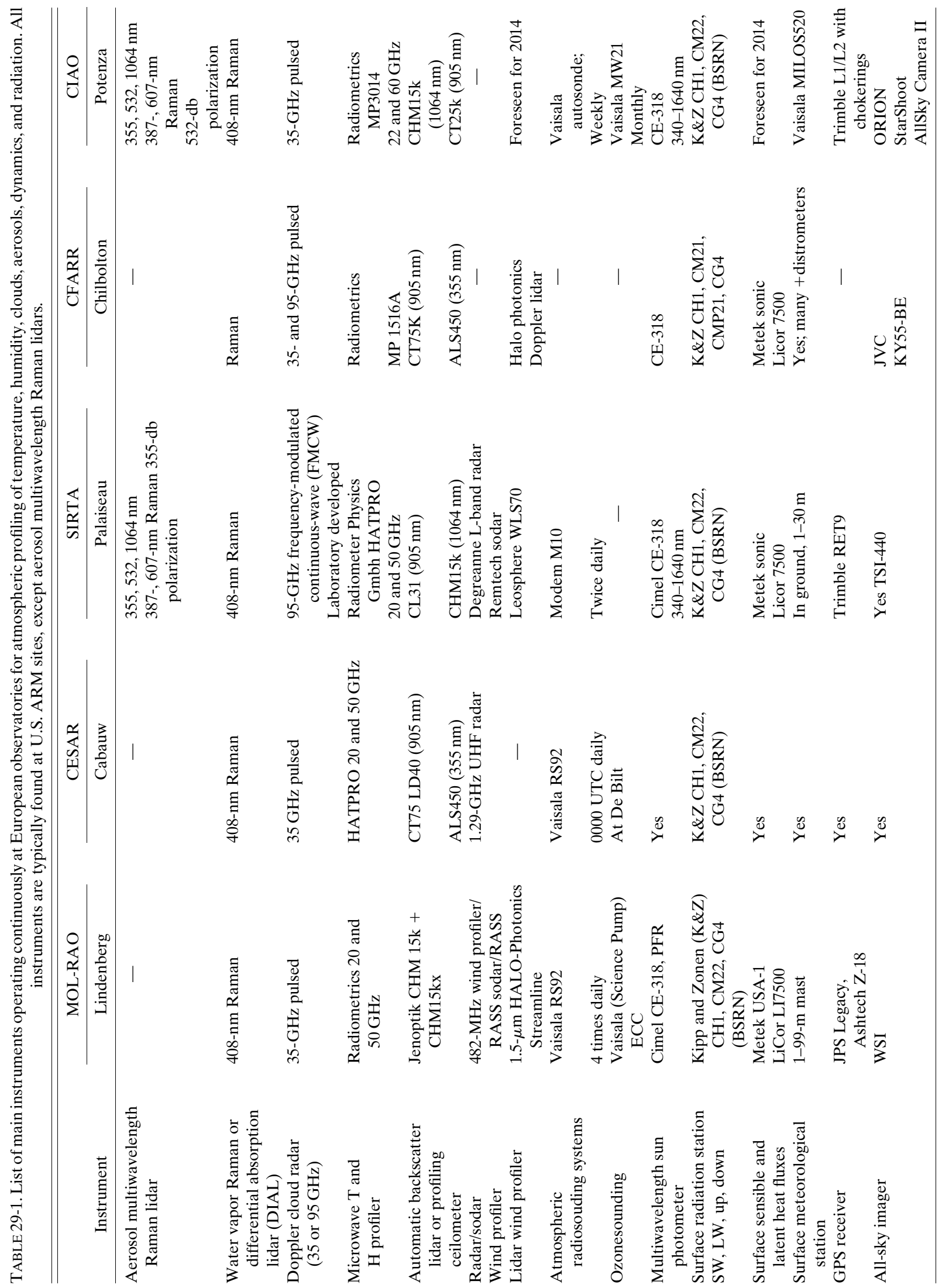



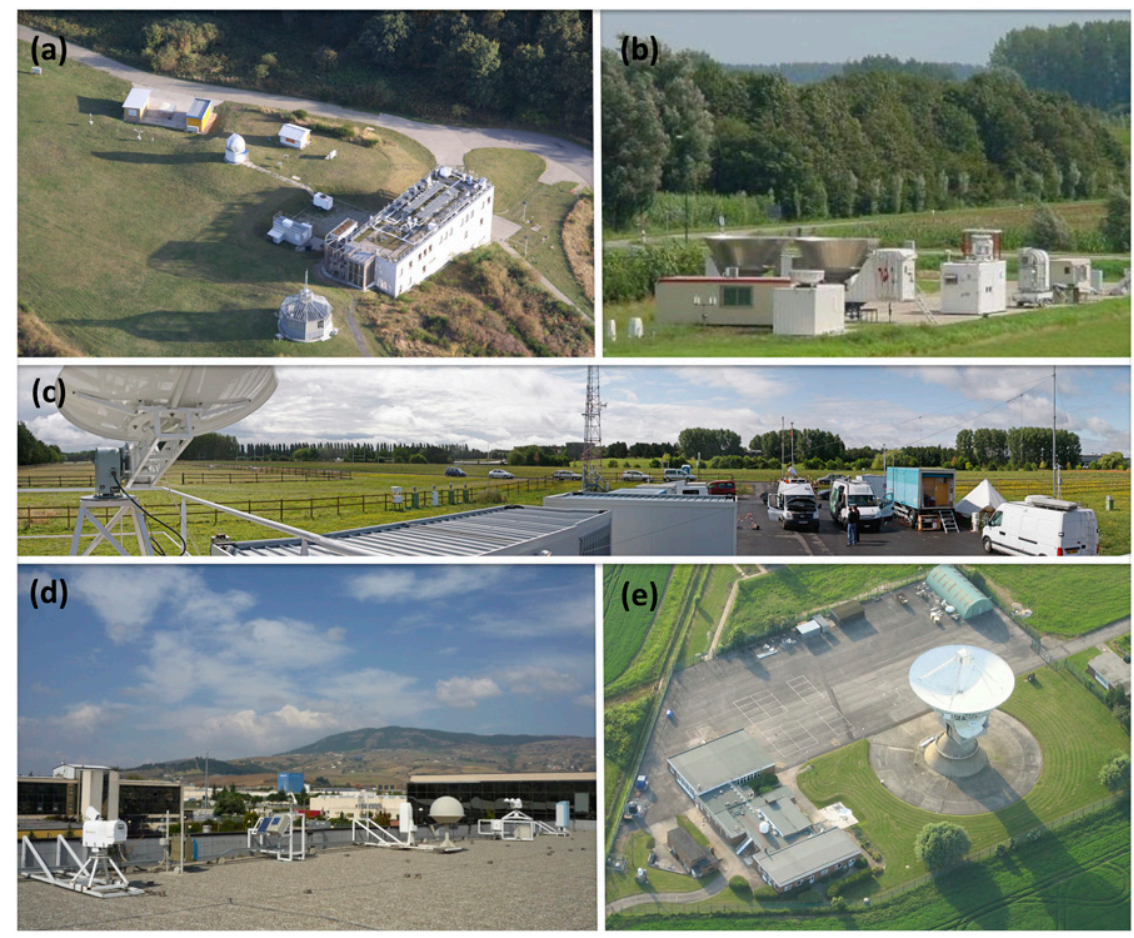

FIG. 29-3. National atmospheric profiling research observatories in Europe: (a) RAO, Lindenberg, Germany; (b) CESAR, the Netherlands; (c) SIRTA atmospheric research observatory, Palaiseau, France; (d) CNR-IMAA atmospheric observatory, Potenza, Italy; (e) CFARR, United Kingdom.

Atmospheric Data Centre and are publicly available. Papers published from 1996 to 2011 have accrued 2307 citations. CFARR plays an important role in student training and was used by 9 Ph.D. students in 2013. Selected scientific highlights and campaigns over the past decade in areas such as cloud overlap, ice cloud physics, mixed-phase clouds, boundary layer dynamics, and volcanic ash are summarized in Table 29-4.

4) THE INSTRUMENTAL Site FOR ATMOSPHERIC Remote SENSING Research in PALAiseau

SIRTA is a French national atmospheric research observatory developed by L'Institut Pierre-Simon Laplace
(IPSL; a research institute in environmental and climate sciences in the Paris metropolitan area) and its partners since the late 1990s (Haeffelin et al. 2005). The observatory is operated by staff from Centre National de la Recherche Scientifique, Ecole Polytechnique, Université Versailles Saint Quentin, Electricité de France, and MétéoFrance, and supported by the French Space Agency. SIRTA is located in a semiurban environment, $25 \mathrm{~km}$ south of the Paris city center $\left(48.72^{\circ} \mathrm{N}, 2.21^{\circ} \mathrm{E}\right.$; see Fig. 29-3c). It operates over 100 sensors, monitoring ground conditions, surface fluxes, and profiles of atmospheric constituents and physical processes (see Table 29-1). Research objectives of SIRTA are to develop comprehensive

TABLE 29-2. Selected research highlights at the CESAR Observatory.

\begin{tabular}{|c|c|c|}
\hline Theme & Highlight description & References \\
\hline Liquid water clouds & $\begin{array}{l}\text { Microphysical properties of water clouds are retrieved and } \\
\text { validated with ground-based shortwave flux measurements. }\end{array}$ & Brandau et al. (2010), Wang et al. (2011) \\
\hline KNMI Test Bed & $\begin{array}{l}\text { Single-column models and LES are confronted with long-term } \\
\text { and continuous observations for a statistical evaluation of } \\
\text { model performance. }\end{array}$ & Neggers et al. (2012) \\
\hline Volcanic ash & $\begin{array}{l}\text { Optical properties of the Eyjafjallajökull ash cloud were } \\
\text { characterized by detailed lidar measurements. }\end{array}$ & Donovan and Apituley (2013) \\
\hline Climate model evaluation & $\begin{array}{l}\text { Aerosol properties in the aerosol-climate model } \\
\text { ECHAM5-HAM were evaluated with CESAR data. }\end{array}$ & Roelofs et al. (2010) \\
\hline
\end{tabular}


TABLE 29-3. Selected research highlights at RAO and the German observatory network.

\begin{tabular}{|c|c|c|}
\hline Theme & Highlight description & References \\
\hline Reference networks & $\begin{array}{l}\text { MOL-RAO is the lead center for GRUAN and a WMO- } \\
\text { Commission on Instruments and Methods of Observation } \\
\text { (CIMO) Lead Centre on process-oriented observations. } \\
\text { Furthermore, it contributes to EUMETNET/E-PROFILE, } \\
\text { BSRN, Instruments and Methods of Observation } \\
\text { Programme (IMOP)/CIMO, GEWEX-Coordinated } \\
\text { Enhanced Observation Period (CEOP), and GEWEX } \\
\text { Atmospheric Boundary Layer Studies (GABLS). }\end{array}$ & $\begin{array}{l}\text { Engelbart and Steinhagen (2001), } \\
\text { Neisser et al. (2002) }\end{array}$ \\
\hline Boundary layer structure & $\begin{array}{l}\text { At MOL-RAO, intensive campaigns to investigate bound- } \\
\text { ary layer structure with additional in situ (including un- } \\
\text { manned aerial vehicles) and remote sensing have been } \\
\text { carried out, e.g., for entrainment studies. At JOYCE, the } \\
\text { typical cumulus cloud-topped boundary layer is analyzed } \\
\text { with respect to stability, turbulence, and cloud properties. }\end{array}$ & $\begin{array}{l}\text { Martin et al. (2014), Löhnert } \\
\text { et al. (2014) }\end{array}$ \\
\hline Snowfall & $\begin{array}{l}\text { Ground-based remote sensing and in situ measurements } \\
\text { used in synergy at the Environmental Station } \\
\text { Schneefernerhouse help to characterize the vertical } \\
\text { distribution of snowfall necessary for satellite retrieval } \\
\text { applications as well as for numerical model evaluation. }\end{array}$ & Löhnert et al. (2011) \\
\hline Mobile stations & $\begin{array}{l}\text { The KITcube consists of in situ and remote sensing systems } \\
\text { including a scanningan X-band rain radar. It was } \\
\text { deployed fully for the first time on the French island of } \\
\text { Corsica during the Hydrological Cycle in the Mediterra- } \\
\text { nean Experiment (HyMeX). Together with LACROS, it } \\
\text { was deployed within the HOPE campaign a triangle of } \\
\text { APROs around JOYCE. }\end{array}$ & $\begin{array}{l}\text { Kalthoff et al. (2013), Bühl et al. } \\
\text { (2013) }\end{array}$ \\
\hline
\end{tabular}

long-term atmospheric observations based on remote sensing and in situ sensors to study atmospheric processes and to analyze regional climate variability. The location of the observatory is designed to study both local/regional-scale processes typical to the urban-rural transition such as the formation mechanisms of gaseous and particulate pollution (Freutel et al. 2013) or the effects of aerosols on fog and shallow cumulus (Haeffelin et al. 2010) under high-pressure situations and largerscale cloud-aerosol processes associated with baroclinic fronts. The SIRTA database is also geared toward global circulation model and numerical weather prediction model evaluations (e.g., Cheruy et al. 2013). Atmospheric process studies frequently take advantage of possible ground and satellite remote sensing synergies (e.g., Protat et al. 2009; Dupont et al. 2010). Selected SIRTA research highlights are presented in Table 29-5.

\section{5) THE CNR-IMAA ATMOSPHERIC OBSERVATORY IN POTENZA}

The Institute of Methodologies for Environmental Analysis (IMAA) of the National Research Council of Italy (CNR) runs the CNR-IMAA Atmospheric Observatory (CIAO). CIAO is located in Tito Scalo, $6 \mathrm{~km}$ from Potenza, in southern Italy, on the Apennine Mountains $\left(40.60^{\circ} \mathrm{N}, 15.72^{\circ} \mathrm{E}, 760 \mathrm{~m} \mathrm{MSL}\right)$ and less than
$150 \mathrm{~km}$ from the west, south, and east coasts. The site is in a plain surrounded by low mountains $(<1100 \mathrm{~m}$ MSL; see Fig. 29-3d). The observatory operates in a typical mountain weather environment strongly influenced by Mediterranean atmospheric circulation, resulting in generally dry, hot summers and cold winters, and is affected by a large number of Saharan dust intrusions each year (Mona et al. 2006).

CIAO represents the most equipped ground-based remote sensing station in the Mediterranean Basin for atmospheric profiling (see Table 29-1; Madonna et al. 2011; Boselli et al. 2012). Since 2000, CIAO is collecting systematic observations of aerosol, water vapor, and clouds. The main scientific objective is the long-term measurement for the climatology of aerosol and cloud properties to provide quality-assured measurements for satellite validation (Mona et al. 2009; Wetzel et al. 2013) and model evaluation (Pappalardo et al. 2004; Villani et al. 2006; Meier et al. 2012) and to fully exploit the synergy and integration of the active and passive sensors for the improvement of the atmospheric profiling (Madonna et al. 2010; Mona et al. 2012). CIAO provides access to data, services, and the research facility for conducting measurements campaigns, and instrument testing, with hundreds of users each year. Selected CIAO research highlights are presented in Table 29-6. 
TABLE 29-4. Selected research highlights at the CFARR Observatory.

\begin{tabular}{|c|c|c|}
\hline Theme & Highlight description & References \\
\hline EarthCARE algorithm validation & $\begin{array}{l}\text { CLARE'98 Campaign. Aircraft flights to validate radar/lidar re- } \\
\text { trievals of clouds for future EarthCARE mission. }\end{array}$ & Hogan et al. (2003b) \\
\hline Rain rates from polarization radar & $\begin{array}{l}\text { First demonstration of improved rainfall estimates and hydrome- } \\
\text { teor identification using polarization diversity radar; these } \\
\text { techniques now implemented on operational radars worldwide. }\end{array}$ & Hall et al. (1984) \\
\hline Cloud overlap & $\begin{array}{l}\text { Measurements and parameterization of the degree of overlap of } \\
\text { clouds and IWC; results implemented in many climate and } \\
\text { weather forecast models worldwide. }\end{array}$ & $\begin{array}{l}\text { Hogan and Illingworth } \\
\quad(2000,2003)\end{array}$ \\
\hline Ice cloud physics & $\begin{array}{l}\text { Doppler radar demonstration that dominant growth mechanism in } \\
\text { ice clouds is aggregation. }\end{array}$ & Westbrook et al. (2010) \\
\hline Ice particle shattering & $\begin{array}{l}\text { Demonstration using Doppler lidar that high concentrations of ice } \\
\text { particles reported from aircraft are an artifact due to shattering. }\end{array}$ & $\begin{array}{l}\text { Westbrook and } \\
\text { Illingworth (2009) }\end{array}$ \\
\hline Mixed-phase clouds & $\begin{array}{l}95 \% \text { of ice in clouds warmer than }-20^{\circ} \mathrm{C} \text { originates via the freezing } \\
\text { of liquid supercooled droplets. }\end{array}$ & $\begin{array}{l}\text { Westbrook and } \\
\text { Illingworth (2011) }\end{array}$ \\
\hline Ice nucleation & $\begin{array}{l}\text { Observations demonstrating that ice nucleation in supercooled } \\
\text { layer clouds is stochastic with a seemingly inexhaustible supply } \\
\text { of ice nuclei. }\end{array}$ & $\begin{array}{l}\text { Westbrook and } \\
\text { Illingworth (2013) }\end{array}$ \\
\hline Boundary layer dynamics & $\begin{array}{l}\text { Use of Doppler lidar observations of vertical velocity skewness and } \\
\text { variance to infer the upward and downward convective forcing in } \\
\text { cloud-topped boundary layer. }\end{array}$ & Hogan et al. (2009b) \\
\hline Turbulence measurement. & $\begin{array}{l}\text { Using Doppler lidar observations in the boundary layer to infer } \\
\text { turbulent kinetic energy dissipation rates. }\end{array}$ & O’Connor et al. (2010) \\
\hline Volcanic ash & $\begin{array}{l}\text { Monitoring of ash with lidar and photometers during Eyjafjalla- } \\
\text { jokull eruption and validation of Met Office dispersion model. }\end{array}$ & Dacre et al. (2011) \\
\hline Convective clouds & $\begin{array}{l}\text { Cloud Storm Initiation Project (CSIP) 2004-05. Large in- } \\
\text { ternational experiment based at Chilbolton to study convective } \\
\text { cloud initiation. }\end{array}$ & Browning et al. (2007) \\
\hline
\end{tabular}

\section{b. European networks of atmospheric profiling observations}

\section{1) ToOls to Structure European ATMOSPHERIC SCIENCE RESEARCH}

The EU Framework Programme for Research and Technological Development is the main instrument for funding research in Europe (Defazio et al. 2009). By funding collaborative projects across Europe, the EU Framework Programme contributed significantly to develop collaboration between atmospheric research communities specializing in profiling atmospheric aerosols, clouds, and radiation in the early 2000s. Three initiatives that allowed construction of durable collaboration on aerosol and cloud profiling across Europe are presented in the three subsections below.

European Cooperation in Science and Technology (COST) is an intergovernmental framework whose goal is to reduce fragmentation in European research investments. COST helps develop cooperation between scientists and researchers across Europe by increasing their mobility through travel funds for meeting and short-term missions. COST Action 720 (2000-06), entitled "Integrated Ground-Based Remote Sensing Stations for Atmospheric Profiling," supported researchers from 12 countries (Engelbart et al. 2009). The main objective of the action was the development and assessment of cost-effective integrated ground-based remote sensing stations for atmospheric profiling of wind, humidity, and clouds. It made important contributions to the development of techniques for integrated profiling systems. COST Action ES0702 (2008-12), entitled "European Ground-Based Observations of Essential Variables for Climate and Operational Meteorology" (EG-CLIMET), supported researchers from 18 countries. The main objective of the EG-CLIMET action was the specification, development, and demonstration of cost-effective ground-based integrated profiling systems suitable for future networks providing essential atmospheric observations for both climate and weather. Following conclusions from the EG-CLIMET action, the European network of national hydrological and meteorological services (EUMETNET) launched a new program called E-PROFILE that will aim at coordinating the provision of calibrated aerosol and cloud profiling data from profiling ceilometers across Europe. This EUMETNET initiative will be accompanied by a new COST action (ES1303, 2013-17) entitled "Towards Operational Ground Based Profiling with Ceilometers, Doppler Lidars and Microwave Radiometers for Improving Weather Forecasts"' (TOPROF). The TOPROF 
TABLE 29-5. Selected research highlights at the SIRTA Observatory.

\begin{tabular}{|c|c|c|}
\hline Theme & Highlight description & References \\
\hline Cloud and fog processes & $\begin{array}{l}\text { Subsidence and lifting of low stratus clouds can be driven by four } \\
\text { different processes: coupling with the surface, changes in cloud-top } \\
\text { radiative cooling, drizzle and precipitation rate, or large-scale } \\
\text { subsidence. }\end{array}$ & $\begin{array}{l}\text { Dupont and Haeffelin (2008), } \\
\text { Dupont et al. (2012), } \\
\text { Haeffelin et al. } 2013\end{array}$ \\
\hline Origin of pollution & $\begin{array}{l}1 / 3 \text { of regional particulate matter concentrations are due to local } \\
\text { emissions, while } 2 / 3 \text { originate from continental transport. The pro- } \\
\text { portion of the transported contribution increases in situations of } \\
\text { high particulate matter concentrations. }\end{array}$ & Zhang et al. (2013) \\
\hline $\begin{array}{l}\text { GCM parameterization } \\
\text { evaluation }\end{array}$ & $\begin{array}{l}\text { Biases in temperature and humidity can be explained by biases in the } \\
\text { partition between surface sensible and latent heat, underestimation } \\
\text { of boundary layer clouds, and insufficient turbulent transport in the } \\
\text { surface layer. }\end{array}$ & Cheruy et al. (2013) \\
\hline Boundary layer structure & $\begin{array}{l}\text { Synergy between lidar backscatter profiles and a Monin-Obukov } \\
\text { length classification derived from sonic anemometer measurements } \\
\text { to reduce uncertainties in daytime and nighttime mixing-height re- } \\
\text { trievals by more than a factor } 2 \text { compared to lidar retrievals alone. }\end{array}$ & $\begin{array}{l}\text { Haeffelin et al. (2012) } \\
\text { Pal et al. (2013) } \\
\text { Cimini et al. (2013) }\end{array}$ \\
\hline Access to the observatory & $\begin{array}{l}\text { The SIRTA Observatory provides nearly } 1000 \text { accesses per year, } \\
\text { where an access is defined as } 1 \text { user (researcher, student, visitor) for } \\
1 \text { day. Users access the observatory mainly }(50 \%) \text { in the framework } \\
\text { of continuous long-term observation programs but also }(25 \%) \text { for } \\
\text { shorter deployments such as field campaigns [e.g., Megacities: } \\
\text { Emissions, Urban, Regional and Global Atmospheric Pollution and } \\
\text { Climate Effects, and Integrated Tools for Assessment and Mitiga- } \\
\text { tion (MEGAPOLI), ParisFog], and } 25 \% \text { for experimental teaching } \\
\text { sessions and outreach. Each year more than } 2500 \text { student hours of } \\
\text { teaching are performed on the observatory. }\end{array}$ & $\begin{array}{l}\text { Freutel et al. (2013) } \\
\text { Haeffelin et al. (2010) }\end{array}$ \\
\hline
\end{tabular}

action aims at developing the procedures to harmonize the provision of data from profiling ceilometers, microwave radiometers, and Doppler lidars.

The last decade has shown rapid advancement in ground-based remote sensing instrumentation being first implemented at reference sites with high potential for larger networks. Because the principles and applications of these instruments are not reflected in past and current university curricula, training activities on various educational levels are required. In addition to training future users, this training also is interesting for small and medium enterprises with growing demand for well-trained personnel. The European Marie Curie Initial Training Network on Atmospheric Remote Sensing (ITARS) aims to bridge the gap between the specialized development of single instruments and atmospheric applications by providing individual training, courses, and summer schools with focus on sensor synergy for early stage and experienced researchers. ${ }^{1}$

\footnotetext{
${ }^{1}$ For the first time ever, ARM hosted a summer workshop in 2015 to train graduate students to use data from ground-based remote sensors. The ARM summer workshop was a follow-on activity from the 2014 ITaRS summer school, which included several ARM principal investigators as instructors.
}

\section{2) THE FP5 CLIWA-NET PROJECT}

The Cloud Liquid Water Network (CLIWA-NET) project (2000-03) was initiated in the context of the EU Baltic Sea Experiment (BALTEX). The objectives of CLIWA-NET were to improve parameterizations of cloud processes in atmospheric models with a focus on vertically integrated cloud liquid water path (LWP) and vertical structure of clouds. To achieve this goal, a prototype of a European Cloud Observation Network was set up, which consisted of 12 ground-based stations and satellite measurements. Because microwave radiometry is the most accurate way to measure liquid water path, more than 10 different microwave radiometers from European universities and research organizations operated successfully during three enhanced observation phases-all part of BRIDGE, the major field experiment of BALTEX. Most importantly, the BALTEX BRIDGE Campaign (BBC; Crewell et al. 2004) included multiple aircraft observations and a microwave intercomparison campaign that served as a baseline to develop an operational microwave radiometer for LWP and thermodynamic profiles (HATPRO; Rose et al. 2005). Methodologies focusing on the evaluation of model-predicted cloud parameters with CLIWA-NET inferred observations were developed and examined in various applications, for example, a statistical evaluation 
TABLE 29-6. Selected research highlights at CIAO.

\begin{tabular}{|c|c|c|}
\hline Theme & Highlight description & References \\
\hline Aerosol & $\begin{array}{l}\text { Characterization of aerosol optical and microphysical properties using } \\
\text { lidar sun photometer and radar measurements. Climatological } \\
\text { studies, long-range transport events, Saharan dust outbreaks, } \\
\text { plumes from volcanic eruptions and for model evaluation and sat- } \\
\text { ellite data validation and integration. }\end{array}$ & $\begin{array}{l}\text { Madonna et al. (2013), } \\
\text { Mona et al. (2012) }\end{array}$ \\
\hline Aerosol-cloud interactions & $\begin{array}{l}\text { Study the variability of aerosol optical properties, relative humidity, } \\
\text { updrafts, and downdrafts in broken thin liquid water clouds with the } \\
\text { aim to gain a better insight in droplet activation process using } \\
\text { Raman lidar, Doppler radar, and microwave radiometer } \\
\text { observations. }\end{array}$ & Rosoldi et al. (2013) \\
\hline Aerosol transport & $\begin{array}{l}\text { Analysis of the physical and dynamical processes related to aerosol } \\
\text { transport as well the validation of the main transport modeled [Dust } \\
\text { Regional Atmospheric Model (DREAM), Navy Aerosol Analysis } \\
\text { and Prediction System (NAAPS), HYSPLIT] using advanced lidar } \\
\text { observations for different aerosol types (e.g., Saharan, volcanic, } \\
\text { biomass burning). }\end{array}$ & $\begin{array}{l}\text { Villani et al. (2006), } \\
\text { Sawamura et al. (2012), } \\
\text { Pappalardo et al. (2013) }\end{array}$ \\
\hline Satellite calibration/validation & $\begin{array}{l}\text { A strategy for EARLINET correlative measurements for CALIPSO } \\
\text { has been developed at CIAO, allowing a reliable statistical analysis } \\
\text { and validation of CALIPSO data. }\end{array}$ & $\begin{array}{l}\text { Mona et al. (2009), } \\
\text { Pappalardo et al. (2010) }\end{array}$ \\
\hline $\begin{array}{l}\text { Advanced statistical analysis of } \\
\text { atmosphere thermodynamics }\end{array}$ & $\begin{array}{l}\text { General and versatile statistical modeling approach to understand to } \\
\text { what extent measurement uncertainty and redundancy are related } \\
\text { to environmental factors, height, and distance has been elaborated } \\
\text { using data from the main highly instrumented station available } \\
\text { worldwide. }\end{array}$ & $\begin{array}{l}\text { Fassò et al. (2014), } \\
\quad \text { Madonna et al. (2014) }\end{array}$ \\
\hline Upper-air measurements & $\begin{array}{l}\text { In situ and ground-based remote sensing measurements in the upper } \\
\text { troposphere are routinely performed to assess long-term trends and } \\
\text { variability, providing traceable measurements with their uncertainty } \\
\text { budget. }\end{array}$ & Mona et al. (2007) \\
\hline Access to the observatory & $\begin{array}{l}\text { CIAO provides nearly } 500 \text { physical accesses per year, where an access } \\
\text { is defined as } 1 \text { user (researcher, student, visitor) for } 1 \text { day accessing } \\
\text { the infrastructure. CIAO provides also open access to its data ar- } \\
\text { chive and to specific services on request. } 60 \% \text { of the access is pro- } \\
\text { vided to European and international users through calibration } \\
\text { services, data processing services, access to data, and physical access } \\
\text { for specific experiments and training activities. International large } \\
\text { field campaigns are organized with international partners in the } \\
\text { framework of EU and international projects/programs. Access to } \\
\text { new users is promoted through dissemination activities (per review } \\
\text { articles, presentations at European and international conferences). } \\
\text { Access to young scientists is promoted through Marie Curie Actions } \\
\text { and European and international schools. }\end{array}$ & $\begin{array}{l}\text { Madonna et al. (2011) } \\
\text { www.ciao.imaa.cnr.it }\end{array}$ \\
\hline
\end{tabular}

of LWP (van Meijgaard and Crewell 2005), the representation of vertically distributed liquid water content (Willen et al. 2005), and comparisons of model-predicted LWP fields with satellite retrieved spatial distributions. Activities to improve temperature and humidity profile retrievals from microwave radiometers were initiated during CLIWA-NET and are described in section 3a.

\section{3) The FP5 Cloudnet PRoJect}

Originally an EU-funded project running from 2001 to 2005 [Fifth Framework Programme (FP5)], the aim of Cloudnet is to provide a systematic evaluation of clouds in forecast models (Illingworth et al. 2007). This evaluation has been achieved by establishing several ground-based remote sensing sites within Europe, which, like those of the U.S. ARM Program, are equipped with an array of instrumentation using active sensors such as lidar and Doppler millimeter-wave radar. These ground-based remote sensing sites provide vertical profiles at high spatial and temporal resolution of the main cloud variables used in forecast models, namely cloud cover and cloud ice and liquid water contents. Previously, the efforts to improve clouds in forecast models had been hampered by the difficulty of making accurate and continuous observations of clouds. Aircraft studies by their nature provide incomplete spatial and temporal studies, and published papers concentrating on case studies may be atypical. 
Following the ethos of the ARM Program, these sites have operated continuously for many years in order to gain statistics and sample the full range of weather phenomena. An important aspect of Cloudnet was the involvement of a number of European operational forecast centers in a cooperative effort to evaluate and improve their skill in cloud predictions. These centers provided profiles of cloud properties hourly for the model grid box over the three original Cloudnet observing stations (see map in Fig. 29-1): CESAR (the Netherlands), CFARR (United Kingdom), and SIRTA (France), but more recently extended to MOL-RAO (Germany) and many other sites as discussed in section $3 \mathrm{c}$. The procedure for deriving cloud properties from ground-based observations for evaluating models is not trivial (e.g., see Shupe et al. 2016, chapter 19). Each of the sites has a different mix of instruments, so a crucial part of Cloudnet has been to devise a uniform set of procedures and data formats to enable the algorithms to be applied at all sites and used to test all models. Cloudnet algorithm developments are presented in section 3a. The core instruments for use in cloud retrievals at each site are a Doppler cloud radar, a lidar ceilometer, a dual- or multiwavelength microware radiometer, and a rain gauge, all operating 24 hours each day. A crucial aspect is to have a common calibration standard for the instruments, so techniques were developed for automatically calibrating cloud lidars (O'Connor et al. 2004) and cloud radar (Hogan et al. 2003a) using the properties of the meteorological targets themselves.

The evaluation of the representation of clouds in seven European operational forecast models as reported by Illingworth et al. (2007) and Bouniol et al. (2010) were quite revealing. In 2003, several gross errors in cloud fraction were identified in some models, but analysis of updated models for the year 2004 showed a considerable improvement. However, a common shortcoming of all models was the lack of midlevel cloud and the inability of many models to produce sufficient occasions when there was $100 \%$ cloud cover. Results are provided in section 3c.

\section{4) THE FP5 AND FP6 EARLINET PROJECTS}

EARLINET was established in 2000 as a research project funded by the European Commission, within the Fifth Framework Programme, with the main goal to provide a comprehensive, quantitative, and statistically significant database for the aerosol distribution on a continental scale. After the end of this project, the network activity continued based on a voluntary association. The 5-yr (2006-11) project EARLINET-Advanced Sustainable Observation System (ASOS) in the Sixth Framework Programme (FP6), starting on the EARLINET infrastructure, has contributed strongly to optimize the operation of the network.
The network started to perform measurements on 1 May 2000 with 22 lidar stations distributed over 14 European countries. Since then, the network has grown both in number of stations and observational capability. Currently, EARLINET consists of 27 lidar stations: 10 single backscatter lidar stations, 8 Raman lidar stations with the UV Raman channel for independent measurements of aerosol extinction and backscatter, and 9 multiwavelength Raman lidar stations (elastic channel at 1064, 532 , and $355 \mathrm{~nm}$; Raman channels at 532 and $355 \mathrm{~nm}$; plus a depolarization channel at $532 \mathrm{~nm}$ ). (A complete list of stations can be found at www.earlinet.org. The locations of these stations are shown as red stars in Fig. 29-1.)

Lidar observations within the network are performed on a regular schedule of one daytime measurement per week around noon, when the boundary layer is usually well developed, and two nighttime measurements per week, with low background light, in order to perform Raman extinction measurements (Matthias et al. 2004a). In addition to the routine measurements, further observations are devoted to monitor special events such as Saharan dust outbreaks (Ansmann et al. 2003; Papayannis et al. 2008), forest fires (Balis et al. 2003) and volcano eruptions (Pappalardo et al. 2013). Since June 2006, additional measurements have been performed at EARLINET stations in coincidence with CALIPSO overpasses according to a strategy for correlative measurements developed within EARLINET (Pappalardo et al. 2010).

Data quality has been assured by instrument intercomparisons using the reference transportable systems (Matthias et al. 2004b). The quality assurance also included the intercomparison of the retrieval algorithms for both backscatter and Raman lidar data (Böckmann et al. 2004; Pappalardo et al. 2004). Moreover, ad hoc tools for the continuous quality check of the instruments and algorithms are used regularly.

The EARLINET database is an important source of data that contributes to the quantification of anthropogenic and biogenic emissions and concentrations of aerosols, quantification of their budgets, radiative properties, and prediction of future trends. It contributes therefore to the improvement of the understanding of physical and chemical processes related to aerosols, their long-range transport and deposition, and their interaction with clouds (e.g., Guibert et al. 2005; Meier et al. 2012).

\section{c. Network of networks}

Since 2000, significant efforts have been made in Europe to establish research infrastructures and networks for atmospheric research. However, only in the EU Seventh Framework Programme was a coordinated research infrastructure for these observations established. 


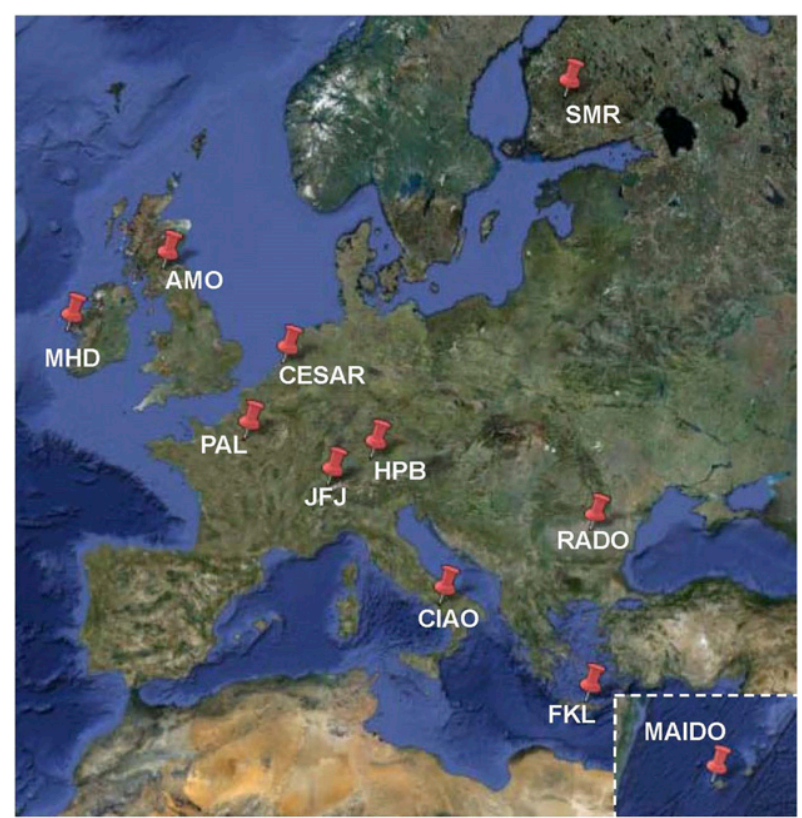

FIG. 29-4. ACTRIS sites offering transnational access.

The ACTRIS network is an outstanding research infrastructure launched in 2011 that aims to coordinate the European ground-based network of stations equipped with advanced atmospheric probing instrumentation for aerosols, clouds, and short-lived trace gases. The main objectives of ACTRIS are the following:

- To provide long-term observational data relevant to climate and air quality research on the regional scale produced with standardized or comparable procedures throughout the network (Fig. 29-1).

- To provide a coordinated framework to support transnational access to large infrastructures (Fig. 29-4) strengthening high-quality collaboration in and outside the European Union and access to high-quality information and services for the user communities (research, environmental protection agencies, etc.).

- To develop new integration tools to fully exploit the use of multiple atmospheric techniques at groundbased stations, in particular for the calibration/validation/ integration of satellite sensors and for the improvement of the parameterizations used in global and regional-scale climate and air quality models.

- To enhance training of new scientists and new users in particular students, young scientists, and scientists from eastern European and non-EU developing countries in the field of atmospheric observation.

- To promote development of new technologies for atmospheric observation of aerosols, clouds, and trace gases through close partnership with EU small and medium enterprises (SMEs).
A key for ACTRIS success is to build a new research infrastructure on the basis of a consortium joining existing networks/observatories that are already providing consistent datasets of observations and that are performed using state-of-the-art measurement technology and data processing.

In particular, the ACTRIS consortium merges two existing research infrastructures funded by the European Commission under FP6: European Supersites for Atmospheric Aerosol Research (EUSAAR) and EARLINET (section 2b). ACTRIS also includes the distributed infrastructure on aerosol interaction existing from the Cloudnet EU research project (section 2b) and by grouping the existing EU ground-based monitoring capacity for short-lived trace gases, which currently is not coordinated at any level-except for the European Monitoring and Evaluation Programme (EMEP) and the Global Atmosphere Watch (GAW) caring for a few specific compounds. Therefore, ACTRIS represents an unprecedented effort toward integration of a distributed network of ground-based stations, covering most climatic regions of Europe, and responding to a strong demand from the atmospheric research community. ACTRIS is a step toward better integration of aerosol, cloud, and trace gases communities in Europe necessary to match the integration of high-quality long-term observations of aerosol, clouds, and short-lived gas-phase species and for assessing their impact on climate and environment. ACTRIS outcomes will be used for supporting decisions in a wide range of policy areas, including air quality, health, international protocols, and research requirements.

\section{EU program initiatives opening to areas of collaboration with the U.S. ARM Program}

Projects funded by the European Commission, presented in sections $2 \mathrm{~b}$ and $2 \mathrm{c}$, allowed European countries to develop and harmonize observation infrastructures. These projects also allowed important scientific developments by supporting the improvement of retrieval methods and algorithms to derive essential climate variables (section 3a), the reanalysis of long-term atmospheric profiling observations to produce quality controlled and harmonized datasets to study climate variability and related atmospheric processes (section $3 \mathrm{~b}$ ), and the development of frameworks including better tools and methods to evaluate weather forecast and climate prediction models (section 3c).

\section{a. Retrieval algorithm developments}

EU research programs associated with atmospheric profiling observatories have focused on the development 

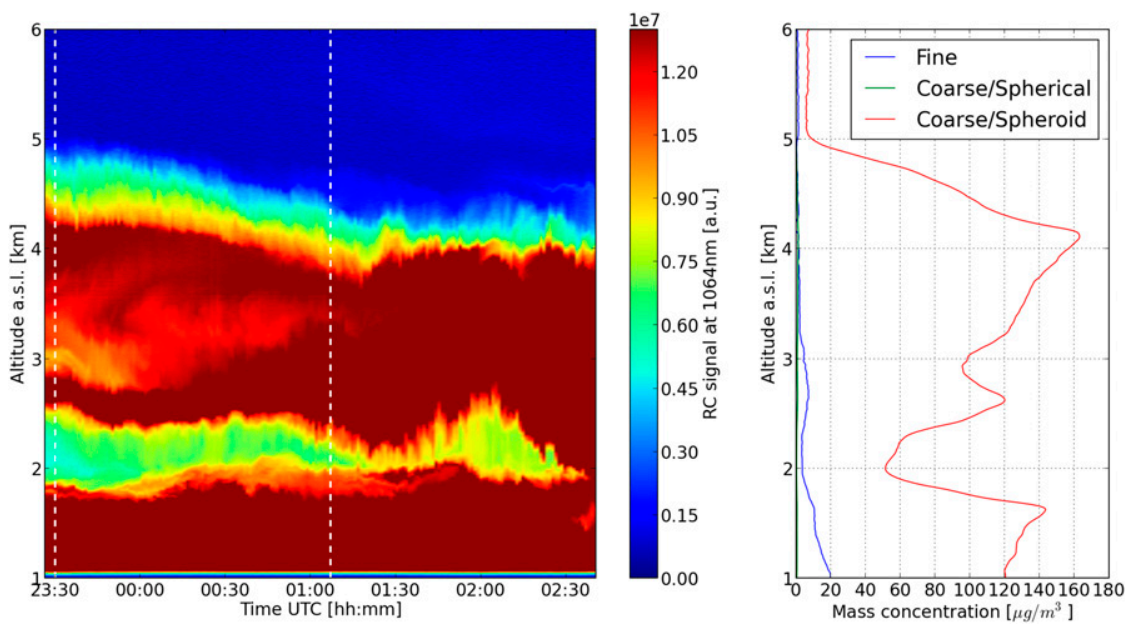

FIG. 29-5. (left) Time evolution of the lidar range-corrected signal at $1064 \mathrm{~nm}$ as measured at CIAO on 4 Sep 2011 during a Saharan dust outbreak. (right) Corresponding mass concentration profiles for fine (blue) and coarse particles, both spherical (green) and spheroid (red) as retrieved using collocated multiwavelength backscatter $(355,532$, and $1064 \mathrm{~nm})$ and depolarization $(532 \mathrm{~nm})$ lidar and sky-scanning radiometer observations. Dashed white lines in (left) indicate the time window for the retrieval reported in (right) (2330 UTC 4 Sep0107 UTC 5 Sep).

of algorithms to retrieve aerosol properties; temperature and humidity profiles; boundary layer height; and cloud properties from radars, lidars, and microwave radiometers. Developments focused on retrievals from sophisticated systems such as multiwavelength Raman lidars and polarized Doppler cloud radars. Recently, low-cost low-power elastic backscatter lidars (profiling ceilometers), profiling microwave radiometers, and continuous-emission cloud radars became available. In Europe alone, several hundred profiling ceilometers are gathering aerosol and cloud backscattering data continuously as national weather services started to build up networks of ceilometers (e.g., Flentje et al. 2010). About 30 microwave profilers are also available, and the potential for low-cost continuous-emission cloud radar networks to develop is high. Hence research developments now also focus on assessing the performance of the low-cost instruments and developing specific retrieval algorithms.

\section{1) Aerosol Profile RETRIEVAls}

Detailed knowledge of optical, microphysical, and radiative properties of aerosol particles is required to understand their role in atmospheric processes as well as their impact on human health and the environment (Forster et al. 2007). The properties must be monitored as a function of time and space, where the vertical dimension is of particular importance because of high variability. Lidar techniques are ideal for collecting rangeresolved data for the characterization of aerosol particles.
EU programs such as EARLINET and ACTRIS provided collaboration frameworks within Europe and strongly supported developments of multiwavelength Raman lidar. These programs also motivated algorithm developments to retrieve aerosol optical properties (backscatter and extinction profiles) as well as microphysical properties (size, shape) and types from Raman lidars. Recent developments now take advantage of the synergy between multiwavelength measurements of lidars and sunphotometers, as illustrated in Fig. 29-5. Examples of developments are presented in Table 29-7.

EU COST actions such as EG-CLIMET and TOPROF also provided useful collaboration frameworks to exploit existing, yet underexploited, low-power automatic backscatter lidars and profiling ceilometers (ALCs). Following spring 2010 when air traffic was disrupted in Europe because of the presence of volcanic ash plumes (e.g., Pappalardo et al. 2013), a renewed interest was gained in the potential of ALCs to retrieve aerosol properties. Techniques for calibrating ALCs and for retrieving backscatter profiles from ALCs developed in the framework of EU programs are presented in Table 29-7.

\section{2) TEMPERATURE AND HUMIDITY PROFILE RETRIEVALS}

Tropospheric temperature and humidity are basic meteorological quantities that determine atmospheric stability. Therefore thermodynamic profiling with high 
TABLE 29-7. Retrieval methods of aerosol properties developed in EU programs.

\begin{tabular}{|c|c|c|}
\hline Retrieved variables & Input data & References \\
\hline $\begin{array}{l}\text { Backscatter coefficient } \\
\text { (from ceilometers) }\end{array}$ & $\begin{array}{l}\text { Ceilometer-attenuated backscatter } \\
\text { profile and optical depth from } \\
\text { sunphotometer }\end{array}$ & $\begin{array}{l}\text { O’ Connor et al. (2004), Markowicz et al. (2008), Flentje et al. } \\
\text { (2010), Heese et al. (2010), Morille et al. (2007), Wiegner and } \\
\text { Geiß (2012), Wiegner et al. (2014) }\end{array}$ \\
\hline $\begin{array}{l}\text { Aerosol backscatter and } \\
\text { extinction }\end{array}$ & Raman lidar & Ansmann et al. $(1990,1992)$ \\
\hline Microphysical properties & Multiwavelength Raman lidars & $\begin{array}{l}\text { Müller et al. (1999), Veselovskii et al. (2002), Böckmann et al. } \\
\text { (2005), Ansmann et al. (2012) }\end{array}$ \\
\hline $\begin{array}{l}\text { Microphysical properties } \\
\text { and aerosol typing }\end{array}$ & $\begin{array}{l}\text { Multiwavelength Raman lidars and } \\
\text { sun photometers }\end{array}$ & $\begin{array}{l}\text { Müller et al. (2004, 2007), Wiegner et al. (2008), Gasteiger et al. } \\
\text { (2011), Mona et al. (2012), Chaikovsky et al. (2012), Pappalardo } \\
\text { et al. (2013), Wagner et al. (2013), Lopatin et al. (2013) }\end{array}$ \\
\hline Giant aerosol & $\begin{array}{l}\text { Multiwavelength Raman lidars and } \\
\text { millimiter-wavelength radars }\end{array}$ & Madonna et al. $(2010,2013)$ \\
\hline
\end{tabular}

temporal and spatial resolution is of high importance for many applications in atmospheric sciences, such as initialization of weather forecasting, model evaluation, and process studies. Radiosonde soundings can provide high vertical resolution profiles along the balloon trajectory but are limited to time intervals of typically $12 \mathrm{~h}$. Therefore, continuous profile observations by unattended remote sensing instruments are of high interest (Carbone et al. 2012) but suffer some drawbacks in vertical resolution and accuracy.

Microwave radiometry is commonly used to derive temperature and humidity profiles from brightness temperature (BT) measurements by applying regressionbased retrieval algorithms relying on a comprehensive prior dataset. BT measurements typically in zenith direction are made at several frequencies along absorption complexes, that is, water vapor and oxygen, requiring a good knowledge on atmospheric absorption characteristics. Kadygrov and Pick (1998) introduced a single frequency technique for boundary layer temperature profiling where different opacities are realized via different elevation angles. To improve accuracy and vertical resolution multifrequency and multiangle measurements can be combined (Crewell et al. 2009). A major advantage of microwave radiometer retrievals is that they are mostly independent on the occurrence of clouds, except for cases of heavy precipitation where saturation effects may occur or when the measurement is influenced by rainwater on the microwave radiometer radome. Infrared spectrometers also can provide thermodynamic profiles but are limited to clear-sky conditions where they are more accurate than the microwave retrievals (Löhnert et al. 2009; Fig. 29-6). However, in the lowest 500-m microwave-derived temperature profiles, derived from elevation scans are as accurate as the infrared retrievals. To optimally exploit the information content of microwave radiometers, variational techniques that combine BT measurements with a priori knowledge and/or auxiliary information have been developed for physically consistent temperature and humidity profiling (Hewison 2007; Cimini et al. 2006). Table 29-8 presents temperature and humidity profile retrieval methods based on microwave radiances developed in the framework of EU programs. Further developments through collaboration with the ARM Program are presented in section $4 b$.

\section{3) MiXING-HEIGHT RETRIEVALS}

The atmospheric mixing height is the height of the layer adjacent to the ground over which constituents emitted within this layer or entrained into it become vertically dispersed by convection or mechanical turbulence within a time scale of about one hour (Seibert et al. 2000). During daytime the mixing layer tends to be unstable as a result of convection and is capped by an entrainment zone. At night a shallow stable layer forms near the surface in which mixing occurs through intermittent turbulence, leaving a residual layer above. Mixing height is a necessary parameter to relate boundary layer concentrations of gases to upstream fluxes and to scale dispersion of trace gases and aerosols for air quality applications.

As pointed out in Seibert et al. (2000), there is no "mixing-height meter" able to determine the mixing height without uncertainties and assumptions. Furthermore, the definitions of mixing layer depend on the geophysical quantity employed in the definition. Because of the importance of this parameter, in the past 20 years, no less than five EU COST actions were at least partially dedicated to better understanding and improving mixing-height retrieval techniques. Table 29-9 provides references to retrieval methods based on radio sounding, lidar, sodar, radar, and microwave radiometers derived in the framework of EU COST actions. The use of instrument synergy allows objective retrievals to be developed as illustrated in Fig. 29-7 (Pal et al. 2013). 

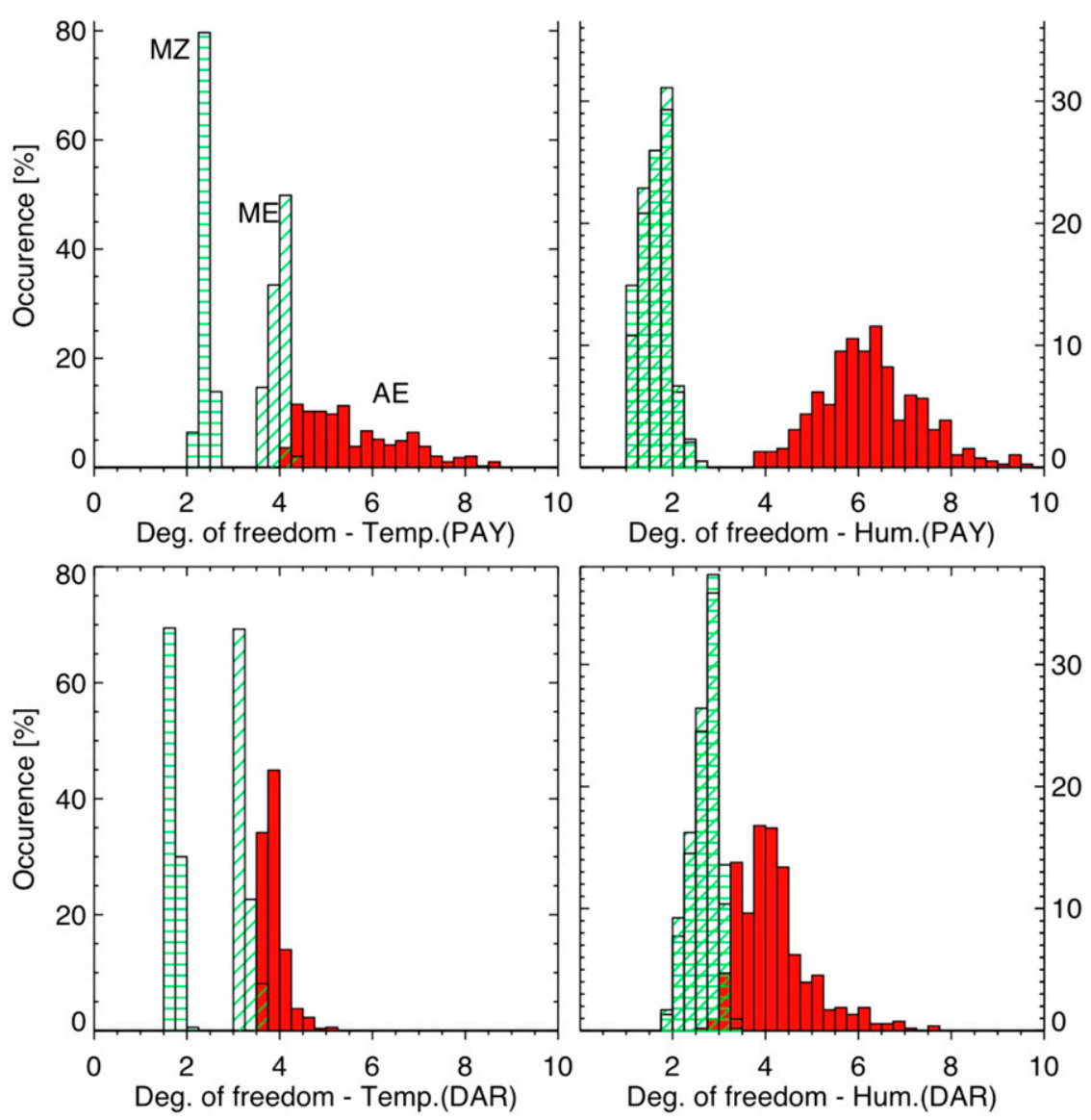

FIG. 29-6. Histograms of the number of degrees of freedom for (left) temperature and (right) humidity retrievals at the (top) Payerne and (bottom) Darwin sites. The different shading indicates the retrieval methods: microwave radiometer zenith only (MZ) in green horizontal lines, microwave radiometer with variable elevation angles (ME) in green slanted lines, and Atmospheric Emitted Radiance Interferometer (AE) in red.

The multi-instrument retrieval techniques could be of interest to derive mixing heights over ARM sites.

\section{4) Cloud profile Retrievals}

Cloud property retrievals derived from cloud radars and lidars were developed in the framework of the EU Cloudnet project (presented in section 2b). These retrieval algorithms use continuous observations by millimetercloud radars, lidar ceilometers, microwave radiometers, and rain gauges to derive values of cloud fraction, ice, and liquid cloud water content (Illingworth et al. 2007). The overall retrieval framework consists of two steps, with the target classification being performed first followed by the microphysical retrievals. The retrieval algorithms were chosen based on their ability to be applied robustly to long periods of data with wellcharacterized errors. The first step in processing is to perform 30-s averaging from each site with the instrument vertical resolution of 30 or $60 \mathrm{~m}$, followed by classifying the target in terms of liquid cloud, ice cloud, rain, aerosol, insects, and combinations thereof. The target classification then guides the retrieval of ice and liquid water content at the instrument resolution. Values of cloud fraction, liquid water content, and ice water content (see Table 29-10 for details) are derived and then averaged onto the vertical grid of each forecast model, and also averaged in time by an amount equivalent to the horizontal resolution of the model given the profile of wind speed. Application of this retrieval scheme to ARM Program measurements is presented in section $4 \mathrm{c}$.

As well as being used for model evaluation, the target classification and microphysical retrievals have been used to study cloud processes. For example, the identification of supercooled water clouds has been used in an analysis (Fig. 29-8) of four years of data at Chilbolton to reveal that $95 \%$ of ice forming at temperatures warmer than $-20^{\circ} \mathrm{C}$ originates via the freezing of liquid drops in supercooled clouds. 
TABLE 29-8. Retrieval methods of temperature and humidity profiles developed in EU programs.

\begin{tabular}{|c|c|c|}
\hline Retrieved variables & Input data & References \\
\hline $\begin{array}{l}\text { Temperature profile (by micro- } \\
\text { wave radiometry) }\end{array}$ & $\begin{array}{l}\text { Brightness temperatures at several frequencies along 60- } \\
\text { GHz oxygen absorption complex taken in zenith } \\
\text { direction }\end{array}$ & Westwater et al. (2005) \\
\hline $\begin{array}{l}\text { Temperature profile with improved } \\
\text { vertical resolution in boundary }\end{array}$ & $\begin{array}{l}\text { Brightness temperatures taken at several elevation angles } \\
\text { along } 60-\mathrm{GHz} \text { oxygen absorption bands }\end{array}$ & \\
\hline \multirow[t]{2}{*}{ layer (by microwave radiometry) } & At a single frequency & Kadygrov and Pick (1998) \\
\hline & At several frequencies & Löhnert and Maier (2012) \\
\hline \multirow[t]{3}{*}{$\begin{array}{l}\text { Humidity profile (by microwave } \\
\text { radiometry) }\end{array}$} & $\begin{array}{l}\text { Brightness temperatures at several frequencies along } \\
\text { water vapor absorption bands }\end{array}$ & \\
\hline & 22-GHz water vapor line & Güldner and Spänkuch (2001) \\
\hline & 183-GHz water vapor line (dry conditions) & Ricaud et al. (2010) \\
\hline $\begin{array}{l}\text { Temperature and humidity pro- } \\
\text { filing (by infrared } \\
\text { interferometry) }\end{array}$ & $\begin{array}{l}\text { Spectral infrared radiance in different bands, spectral ob- } \\
\text { servations: } 612-713 \text { and } 2223-2260 \mathrm{~cm}^{-1} \text { (i.e., } 15-\text { and } \\
4.3-\mathrm{mm} \mathrm{CO}_{2} \text { bands, respectively) for temperature pro- } \\
\text { filing; } 538-588 \text { and } 1250-1350 \mathrm{~cm} \mathrm{~cm}^{-1} \text { for water vapor }\end{array}$ & Spänkuch et al. (1996) \\
\hline \multirow{2}{*}{$\begin{array}{l}\text { Temperature and humidity profiles } \\
\text { (1D VAR method) }\end{array}$} & \multirow{2}{*}{$\begin{array}{l}\text { Brightness temperatures along } 22.235-\mathrm{GHz} \text { water vapor } \\
\text { absorption and } 60 \mathrm{GHz} \text {, ambient temperature and hu- } \\
\text { midity, infrared temperature }\end{array}$} & Hewison (2007) \\
\hline & & Cimini et al. (2006) \\
\hline $\begin{array}{l}\text { Temperature and humidity pro- } \\
\text { files, LWC (IPT method) }\end{array}$ & $\begin{array}{l}\text { Brightness temperatures along } 22.235-\mathrm{GHz} \text { water vapor } \\
\text { absorption and } 60-\mathrm{GHz} \text { oxygen absorption complex, } \\
\text { cloud radar reflectivity profile }\end{array}$ & Löhnert et al. (2008) \\
\hline
\end{tabular}

\section{5) SYNERGETIC LIQUID CLOUD PROFILE RETRIEVALS AND BLIND TEST INITIATIVE}

State-of-the-art liquid cloud profile retrievals typically use information from cloud radar, microwave radiometer (MWR) and lidar to retrieve liquid cloud parameters like liquid water content, cloud droplet number concentration $(N)$, effective radius $\left(R_{\text {eff }}\right)$, and cloud optical depth (COD). Various methods to retrieve these properties exist and may differ in the measurements used and assumptions made. Some methods combine cloud radar and MWR information, for example, the Technical University Delft Remotely-Sensed Cloud Property Profiles (TUD-RSCCP) algorithm (Brandau et al. 2010) or the integrated profiling technique (IPT; Löhnert et al. 2004; Löhnert et al. 2008). In contrast to TUD-RSCCP

TABLE 29-9. Mixing-height retrieval methods developed in EU programs.

\begin{tabular}{|c|c|c|}
\hline Retrieved variables & Input data & References \\
\hline Mixing height from numerical model output & $\begin{array}{l}\text { Parameterizations in meteorological } \\
\text { preprocessors }\end{array}$ & $\begin{array}{l}\text { COST Action } 710 \\
\text { Fisher et al. (1998), Seibert et al. (2000) }\end{array}$ \\
\hline Mixing height from measurements & $\begin{array}{l}\text { Radiosonde profiles, sodar, and wind } \\
\text { profiler measurements }\end{array}$ & $\begin{array}{l}\text { COST Action } 710 \\
\text { Seibert et al. }(2000)\end{array}$ \\
\hline $\begin{array}{l}\text { Urban mixing height from numerical } \\
\text { model output and measurements }\end{array}$ & $\begin{array}{l}\text { Mesoscale numerical simulations } \\
\text { Radiosonde profiles and sodar } \\
\text { measurements }\end{array}$ & $\begin{array}{l}\text { COST Action } 715 \\
\text { Fisher et al. (2001) } \\
\text { Piringer et al. (2007) }\end{array}$ \\
\hline $\begin{array}{l}\text { Mixing height from surface-based } \\
\text { remote sensing }\end{array}$ & $\begin{array}{l}\text { Sodar, radar, and lidar profiling } \\
\text { measurements }\end{array}$ & Emeis et al. (2008) \\
\hline \multirow[t]{3}{*}{ Mixing height traced by aerosols } & $\begin{array}{l}\text { Attenuated backscatter profiles mea- } \\
\text { sured by automatic lidars and } \\
\text { ceilometers }\end{array}$ & $\begin{array}{l}\text { COST Action ES0702 } \\
\text { [Structure of the Atmosphere } \\
\text { (STRAT) methods] }\end{array}$ \\
\hline & Backscatter profiles alone & Haeffelin et al. (2012) \\
\hline & $\begin{array}{l}\text { Backscatter and surface stability condi- } \\
\text { tions derived from sonic anemometers }\end{array}$ & Pal et al. (2013) \\
\hline \multirow[t]{2}{*}{ Mixing height traced by temperature profilers } & $\begin{array}{l}\text { Microwave radiometer temperature } \\
\text { profiles }\end{array}$ & COST Action ES0702 \\
\hline & Microwave brightness temperatures & Cimini et al. (2013) \\
\hline Mixing-height dynamics using Doppler lidar & $\begin{array}{l}\text { Vertical velocity profiles and velocity } \\
\text { variance profiles }\end{array}$ & Barlow et al. (2011) \\
\hline Boundary layer types & $\begin{array}{l}\text { Vertical velocity profiles and velocity } \\
\text { variance profiles }\end{array}$ & Harvey et al. (2013) \\
\hline
\end{tabular}




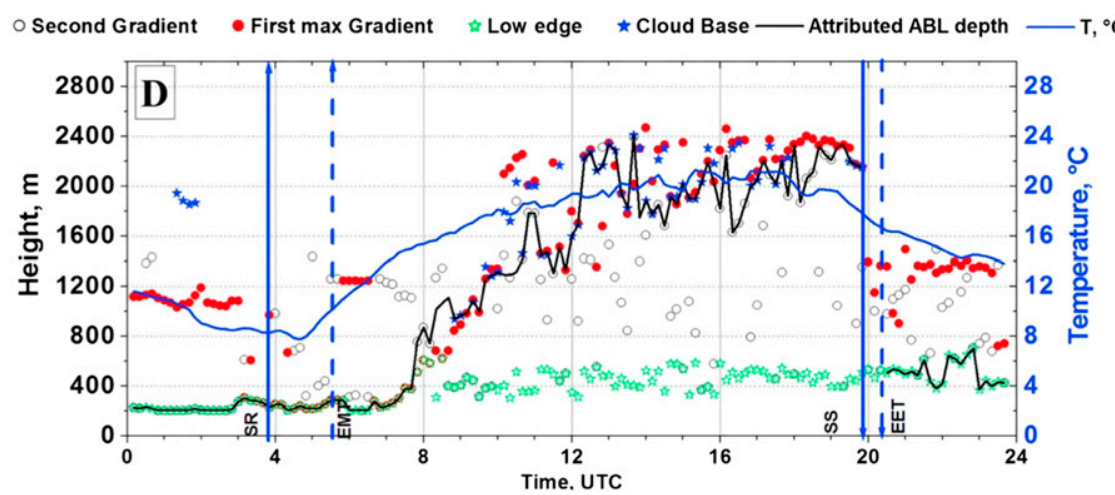

FIG. 29-7. Ceilometer-attenuated backscatter gradients (black circles, red circles, and green stars); cloud-base height (blue stars); attributed mixing height (black line); air temperature (blue line); sunrise (SR) and sunset (SS)—vertical blue solid lines; early morning transition (EMT) and early evening transition (EET) — vertical blue dashed lines. Parameters are derived from lidarattenuated backscatter and sonic anemometer measurements at the SIRTA Observatory.

and IPT, the synergistic remote sensing of cloud (SYRSOC) algorithm (Martucci and O'Dowd 2011; Martucci et al. 2012) also makes use of lidar observations (see Table 29-11 for more information on the algorithms). Within the EG-CLIMET COST action (http://www.cost. eu/COST_Actions/essem/ES0702), the above-listed algorithms were assessed thoroughly via an observing system simulation experiment (OSSE). Using synthetic observations based on scenes from cloud-resolving model output, an independent evaluation of the different retrieval algorithms was conducted. All methods are very sensitive to the correct description of the cloud boundaries and the correct discrimination between cloud droplets and precipitation. The accuracy of the SYRSOC liquid water content depends on the accuracy of the retrieved lidar extinction. For nonprecipitating cases, the TUD-RSCCP method provides the best results with accuracy in liquid water content of $\sim 15 \%$ (Fig. 29-9). In precipitating cases, drizzle drops dominate the radar reflectivity factor signal resulting in an overestimation (underestimation) of the effective radius (droplet number concentration). However, both IPT and TUDRSCCP still provide robust results for the liquid water content with errors in the range of $20 \%-50 \%$.

During the EU-DOE Ground-Based Cloud and Precipitation Retrieval Workshop, which took place on
13-14 May 2013 in Cologne, it was decided that an extended experiment within the same framework that would also include DOE ARM retrieval algorithms would be conducted in the future.

\section{b. Long-term climate datasets}

Atmospheric profiling observatories are useful for modeling applications and climate studies, in particular because local processes can be used to explain the seasonal and interannual variability of climate (e.g., Chiriaco et al. 2014). Nevertheless, climate trends or variability cannot be detected in a dataset if the climate signal is less than the measurement biases. These biases must be reduced using specific procedures. The data from each APRO must be reprocessed carefully to include better quality control and better retrieval algorithms, to make use of instrument synergy, to reduce biases, and to evaluate uncertainties and spatial representativeness. Further, APRO data must be harmonized in temporal and vertical grids and must follow naming conventions and commonly adopted user-friendly formats. This work consists in reanalyzing the original data to reach a high level of harmonization and standardization.

Ad hoc activities within the U.S. and European atmospheric observation communities have been initiated to produce comprehensive datasets of clouds, radiation,

TABLE 29-10. Retrievals of cloud profiles developed in the EU Cloudnet program.

\begin{tabular}{|c|c|c|}
\hline Retrieval variables & Input data & References \\
\hline Cloud fraction & $\begin{array}{l}\text { Cloud radar, ceilometer; fraction of pixels in model grid box } \\
\text { classified as cloud }\end{array}$ & Illingworth et al. (2007) \\
\hline LWC & $\begin{array}{l}\text { Cloud radar and ceilometer for cloud top and base: assume linear } \\
\text { LWC with height scaled to agree with water path from radiometer }\end{array}$ & Illingworth et al. (2007) \\
\hline IWC & Cloud radar reflectivity corrected for attenuation by LWC and humidity & Hogan et al. (2006) \\
\hline Drizzle rate & Radar reflectivity and lidar backscatter & O’Connor et al. (2005) \\
\hline
\end{tabular}




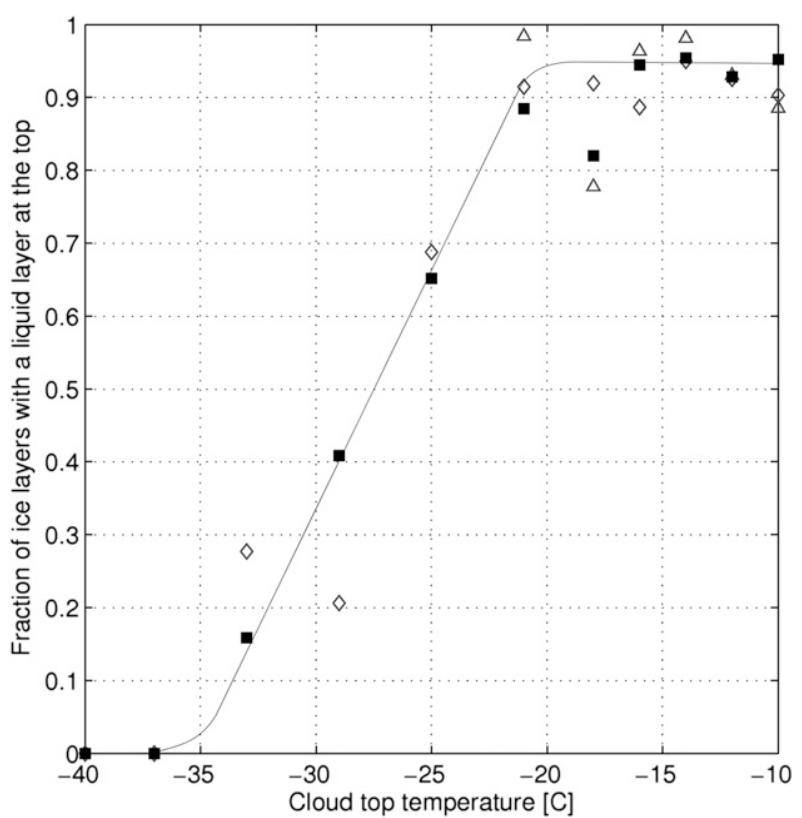

FIG. 29-8. The fraction of ice clouds containing liquidlike layers as a function of cloud-top temperature derived from four years of continuous observations at CFARR. To test the sensitivity of the identification of supercooled water and ice from radar and lidar observations, the diamonds are for data when the $\mathrm{dBZ}$ radar threshold was increased from -20 to $-10 \mathrm{dBZ}$ to ensure that no liquid droplet clouds are being diagnosed as containing ice. The triangles are for cases when the presence of ice was confirmed by specular reflection from oriented ice particles.

and atmospheric profiles for driving and evaluating large-eddy simulation (LES) models, for assessing climate model simulations and NWP forecasts, and for performing climate studies and climate feedback analyses. The U.S. ARM Program developed a dataset specifically designed for modelers to evaluate climate models. This dataset, called ARM Climate Modeling Best Estimate (CMBE; Xie et al. 2010), consists of a dozen cloud and radiation quantities provided as hourly averages, standard deviations within each hour, and quality control flags to qualify data quality and temporal variability. CMBE products were derived from data at each ARM observation facility.

In Europe, a similar initiative was started in the frame of the European Union Cloud Intercomparison, Process Study and Evaluation (EUCLIPSE) Project (see section $3 c$ ). A dataset was developed from data gathered at the observatories of CESAR (only EUCLIPSE period for now), CFARR (only EUCLIPSE period for now), and SIRTA (all the available period, starting in 2002 for the earliest observations). The European Climate Testbed Dataset (ECTD) includes meteorological parameters, cloud and surface fluxes parameters, and instrument observables. For each parameter, a retrieval algorithm was identified to harmonize data interpretation across the three observatories. A quality control procedure was developed for each parameter. Spatial representativeness was evaluated over a $50-\mathrm{km}$ domain around the observatory using observations from standard meteorological stations. Similarly to the CMBE dataset, ECTD provides data as hourly averages, standard deviations within each hour, and quality control flags to qualify data quality and temporal and spatial variability. Data files are in netCDF format, which includes all necessary metadata associated with each parameter. An important feature is that the ECTD data nomenclature (names of geophysical variables) is made consistent with the ARM CMBE nomenclature and the nomenclature used by CMIP5 climate models. A description of the ECTD of the SIRTA Observatory is provided in Cheruy et al. (2013) and Chiriaco et al. (2014), including a description of the quality control procedure. Table 29-12 provides the content of the SIRTA file (available online at http://sirta.ipsl.polytechnique.fr/sirta.old/reobs.html).

EU and U.S. scientists have recognized that there is a strong need to have these activities coordinated in a better way so that U.S. and EU datasets have common retrieval methods, data formats, naming conventions, common grids, etc. This coordination would help increase the number of studies that make combined use of EU and U.S. APRO datasets. As suggested during the

TABLE 29-11. Liquid cloud retrievals that participated in the OSSE within the EG-CLIMET COST Action.

\begin{tabular}{|c|c|c|}
\hline Retrieved variables & Input data & References \\
\hline $\begin{array}{l}\mathrm{LWC}, \mathrm{N}, \mathrm{R}_{\mathrm{eff}}, \mathrm{COD} \text {, aerosol } \\
\text { indirect effect index }\end{array}$ & $\begin{array}{l}\text { Lidar extinction profile, } \mathrm{T} \text { and } \mathrm{q} \text { profiles } \\
\text { from MWR, LWP from MWR, } \mathrm{Z} \text { and linear } \\
\text { depolarization ratio (LDR) from cloud radar }\end{array}$ & $\begin{array}{l}\text { SYRSOC (Martucci and O’Dowd 2011; } \\
\text { Martucci et al. 2012) }\end{array}$ \\
\hline LWC & $\begin{array}{l}\mathrm{T} \text { and p profiles, LWP from MWR, Cloudnet } \\
\text { classification product }\end{array}$ & $\begin{array}{l}\text { Cloudnet scaled-adiabatic LWC } \\
\text { (Illingworth et al. 2007) }\end{array}$ \\
\hline LWC, N, $\mathrm{R}_{\mathrm{eff}}, \mathrm{COD}$ & $\begin{array}{l}\mathrm{Z} \text { from cloud radar, cloud base from lidar, } \\
\text { LWP from MWR }\end{array}$ & TUD-RSCCP (Brandau et al. 2010) \\
\hline LWC, LWP, T, and q profiles & $\begin{array}{l}\mathrm{Z} \text { from cloud radar, brightness temperatures } \\
\text { from MWR, prior information on LWC, T, } \\
\text { and q profiles }\end{array}$ & IPT (Löhnert et al. 2004, 2008) \\
\hline
\end{tabular}



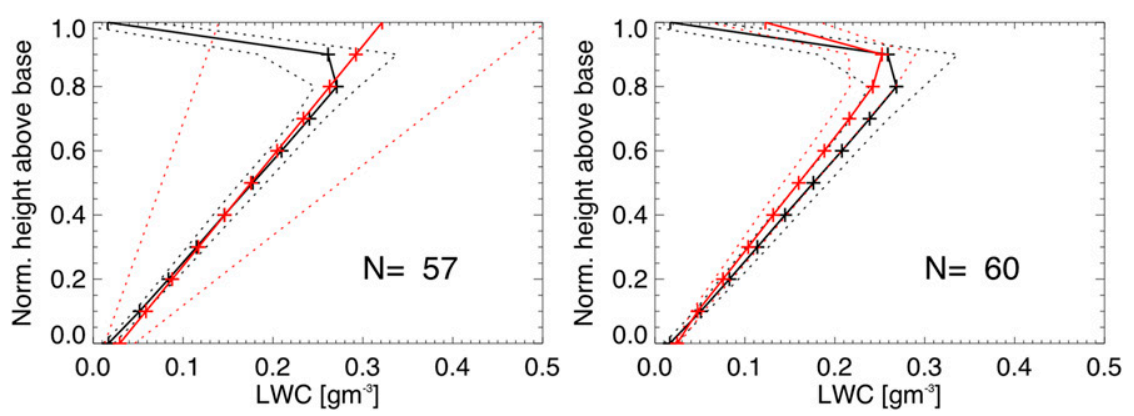

FIG. 29-9. Mean LWC profile from cloud-resolving model output (thick black) and corresponding $1 \sigma$ range (dotted black) for a simulation initialized over the CESAR Observatory (the Netherlands). The red lines show results and corresponding $1 \sigma$ ranges from (left) the Cloudnet scaled-adiabatic method and (right) the TUD-RSCCP method.

U.S.-EU workshop (DOE-Climate and Environmental Sciences Division 2013), a data-harmonization working group should be created to address these data issues, specifically for applications that require use of long-term multiparameter datasets.

\section{c. Climate and weather model evaluation initiatives}

Existing observations from routine measurements or long field campaigns carried out at atmospheric profiling observatories can be used to evaluate models on synoptic, seasonal, interannual, and now even climatic time scales at a relatively low cost. Such continuous evaluation is complementary to detailed case studies performed with 1D versions of climate models or with cloud-resolving models and large-eddy simulations carried out on highly documented cases obtained during focused field experiments. Long-term or continuous evaluations offer more representative evaluations to identify limitations in physical parameterizations of models, to evaluate the impact of modified parameterizations, and to confront the behavior of different models on different observatories. We present three examples of model evaluation frameworks developed in Europe that use long-term observations from atmospheric profiling observatories: the Cloudnet framework to evaluate NWP models, the KNMI Parameterization Test Bed (KPT) framework for single-column and climate model evaluations, and the EUCLIPSE framework to develop datasets for the International Climate Model Intercomparison Project.

\section{1) Cloudnet NWP model evaluations}

A framework for continuous evaluation of NWP models was developed in the EU Cloudnet project described in sections 2a and 2b. As an example of Cloudnet model evaluation, Fig. 29-10b shows that in 2004 the profiles of mean ice water content (IWC) and the probability distribution of IWC in European operational forecast models were generally in fair agreement with the observations. It can be seen that the Met Office mesoscale and the ECMWF model reproduce the mean IWC within the uncertainty of the IWC retrieval. Below $0.1 \mathrm{~g} \mathrm{~m}^{-3}$, the DWD model has the best representation of the PDF, but because it treats falling snow as a separate noncloud variable, it predicts virtually no IWC above this, thus the mean IWC below $7 \mathrm{~km}$ is substantially underestimated. Both the Météo-France and Met Office global models have too low a mean value of IWC mainly because they are simulating too narrow a distribution of the IWC. As part of the ACTRIS FP7 project, the Cloudnet analysis system is being extended to cover more sites within Europe and to implement new model evaluation metrics. Many European forecast models are now carrying aerosol loading as prognostic variables, and the first steps are now being made to compare the forward-modeled lidar backscatter profiles of the aerosols with those observed by Cloudnet. This also raises the possibility of assimilating the observations in real time.

New techniques have been developed for evaluating models. For example, Barrett et al. (2009) compared diurnal composites of observed and modeled stratocumulus clouds and found that models with a nonlocal mixing scheme and an explicit formulation for cloud-top entrainment had the best diurnal cycle of cloud occurrence. New approaches have been developed for evaluating not just the climatological occurrence of clouds in models but their ability to forecast them at the right time and location. The equitable threat score (ETS) is used widely in forecast verification but Hogan et al. (2009a, 2010) pointed to several inherent problems with ETS. Most important is that the ETS value depends upon the frequency of occurrence and tends to zero for increasingly rare events. Cloud occurrence decreases rapidly toward the troposphere leading to a misleading drop in the value of ETS. They proposed a new metric, the symmetric extreme dependency score, which avoids these problems and is being implemented within Cloudnet. 
TABLE 29-12. List of parameters currently included in the ECTD. ECTD variable names, equivalent ARM CMBE nomenclature, units, and description.

\begin{tabular}{|c|c|c|c|c|}
\hline Variable & $\begin{array}{c}\text { ARM CMBE } \\
\text { name }\end{array}$ & Description & $\begin{array}{l}\text { Period } \\
\text { of obs. }\end{array}$ & Reference \\
\hline tas & T_sfc & 2-m air temperature, $\mathrm{K}$ & $2003-16$ & - \\
\hline hurs & rh_sfc & $2-\mathrm{m}$ relative humidity, $\%$ & $2003-16$ & - \\
\hline huss & - & 2-m specific humidity, $\mathrm{kg} \mathrm{kg}^{-1}$ & $2003-16$ & - \\
\hline psl & - & Sea-level pressure, $\mathrm{Pa}$ & $2003-16$ & - \\
\hline sfcWind & wspd_sfc & 2-m wind speed, $\mathrm{m} \mathrm{s}^{-1}$ & $2003-16$ & - \\
\hline vas & v_sfc & 2-m northward wind, $\mathrm{m} \mathrm{s}^{-1}$ & $2003-16$ & - \\
\hline uas & u_sfc & 2-m eastward wind, $\mathrm{m} \mathrm{s}^{-1}$ & $2003-16$ & - \\
\hline $\mathrm{pr}$ & prec_sfc & precipitation at surface, $\mathrm{kg} \mathrm{m}^{-2} \mathrm{~s}^{-1}$ & $2003-16$ & - \\
\hline visi & - & visibility, m & $2010-16$ & - \\
\hline rlds & lwdn & Surface downwelling longwave radiation, $\mathrm{W} \mathrm{m}^{-2}$ & $2003-16$ & - \\
\hline rlus & lwup & Surface upwelling longwave radiation, $\mathrm{W} \mathrm{m}^{-2}$ & $2007-16$ & - \\
\hline rsds & swdn & Surface downwelling shortwave radiation, $\mathrm{W} \mathrm{m}^{-2}$ & $2003-16$ & - \\
\hline rsus & swup & Surface upwelling shortwave radiation, $\mathrm{W} \mathrm{m}^{-2}$ & $2007-16$ & - \\
\hline hfss & $\mathrm{SH}$ & Surface upward sensible heat flux, $\mathrm{W} \mathrm{W} \mathrm{m}^{-2}$ & $2006-16$ & - \\
\hline hfls & LH & Surface upward latent heat flux, $\mathrm{W} \mathrm{m}^{-2}$ & $2006-16$ & - \\
\hline saa & - & solar azimuthal angle, ${ }^{\circ}$ & $2003-16$ & - \\
\hline sza & - & solar zenithal angle, ${ }^{\circ}$ & $2003-16$ & - \\
\hline Stx ${ }^{\mathrm{a}}$ & - & Soil temperature $x \mathrm{~cm}$ below ground level, $\mathrm{K}$ & $2007-16$ & - \\
\hline $\mathrm{Smx}^{\mathrm{a}}$ & - & Soil moisture $x \mathrm{~cm}$ below ground level, $\mathrm{g} \mathrm{cm}^{-3}$ & $2007-16$ & - \\
\hline channel_x_mean ${ }^{\mathrm{b}}$ & - & Mean brightness temperature from MSG at $x \mu \mathrm{m}, \mathrm{K}$ & $2005-10$ & - \\
\hline cf_nfov & - & Lidar cloud fraction & $2008-13$ & Morille et al. (2007) \\
\hline rsdscs & - & Surface downwelling shortwave radiation for clear sky, $\mathrm{W} \mathrm{m}^{-2}$ & $2003-16$ & Long et al. (2006) \\
\hline rldscs & - & Surface downwelling longwave radiation for clear sky, $\mathrm{W} \mathrm{m}^{-2}$ & $2003-16$ & Long et al. (2006) \\
\hline tot_cld_tsi & tot_cld_tsi & Cloud fraction from sky imager & $2009-16$ & - \\
\hline cflw & - & Cloud fraction from longwave radiation & $2003-16$ & Long et al. (2006) \\
\hline cfsw & - & Cloud fraction from shortwave radiation & $2003-16$ & Long et al. (2006) \\
\hline $\mathrm{Cbhx}^{\mathrm{c}}$ & - & Lidar cloud base heigh, $\mathrm{m}$ & $2008-13$ & Morille et al. (2007) \\
\hline aot_x $x^{d}$ & - & Aerosol optical thickness at $x \mathrm{~nm}$ & $2003-16$ & Holben et al. (1998) \\
\hline lwp & - & liquid water path, $\mathrm{g} \mathrm{m}^{-2}$ & $2010-16$ & - \\
\hline mld & - & mixing layer depth, $\mathrm{m}$ & $2008-13$ & Pal et al. (2015) \\
\hline water & - & Clear sky integrated water vapor, $\mathrm{kg} \mathrm{m}^{-2}$ & $2003-16$ & Holben et al. (1998) \\
\hline x_yangstrom ${ }^{\mathrm{e}}$ & - & Angstrom exponent between $x$ and $y \mathrm{~nm}, \mathrm{~nm}$ & $2003-16$ & Holben et al. (1998) \\
\hline cld_frac & - & Percentage cloudy pixels over $15 \times 15$ pixels & $2005-10$ & Roebeling et al. (2006) \\
\hline clwp_mean & - & Mean cloud liquid water path over $15 \times 15$ pixels, $\mathrm{g} \mathrm{m}^{-2}$ & $2005-10$ & Roebeling et al. (2006) \\
\hline ctt_mean & - & Mean cloud top temperature over $15 \times 15$ pixels, $\mathrm{K}$ & $2005-10$ & Roebeling et al. (2006) \\
\hline reff_mean & - & Mean cloud effective radius over $15 \times 15$ pixels, $\mathrm{mm}$ & $2005-10$ & Roebeling et al. (2006) \\
\hline tau_mean & - & Mean cloud optical thickness over $15 \times 15$ pixels, $\mathrm{g} \mathrm{m}^{-2}$ & $2005-10$ & Roebeling et al. (2006) \\
\hline SR & - & Lidar scattering ratio vertical histograms & $2003-16$ & - \\
\hline Strat & - & Lidar STRAT classification vertical histograms & $2003-16$ & Morille et al. (2007) \\
\hline Molecular & - & Lidar molecular profile & $2003-16$ & - \\
\hline Alt norm & - & Altitude of normalisation of lidar profiles, $\mathrm{m}$ & $2003-16$ & - \\
\hline
\end{tabular}

${ }^{\text {a }} x$ is $5,10,20,30,50 \mathrm{~cm}$

${ }^{\mathrm{b}} x$ is $12,0.6,0.8,1.6,3.8,10.8 \mu \mathrm{m}$

${ }^{\mathrm{c}} x$ is first layer (1), second layer (2), third layer (3)

${ }^{\mathrm{d}} x$ is $1020,870,675,500,440,380,340 \mathrm{~nm}$

${ }^{\mathrm{e}} x$ and $y$ are the interval between ${ }^{\mathrm{d}}$ values.

Hogan et al. (2009a) used this score to show that the "half life" of a cloud forecast (the time into the forecast at which, on average, the score fell to half of its initial value) was 2.5-4.5 days rather than around 9 days for a pressure forecast. Operational forecast models within Europe are introducing more advanced cloud and aerosol parameterizations with additional variables, but there is a risk that if the new variables are not constrained by observations, they can actually degrade the forecast. Comparison of skill scores of forecasts with and without the new variables should reveal if they are leading to a more realistic representation of cloud/aerosol interactions.

\section{2) KNMI PARAMETERIZATION TEST BED}

Diabatic processes like turbulence, convection, clouds, and radiation still are represented insufficiently in 


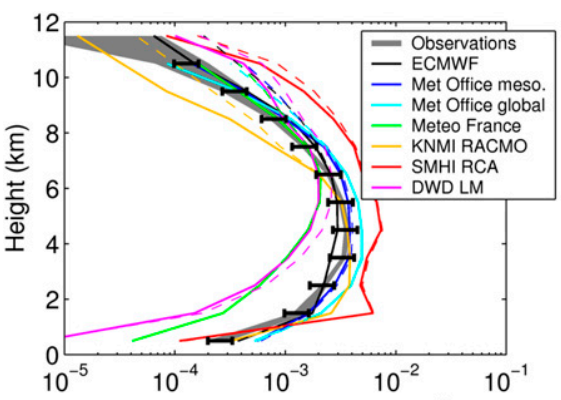

(a) Mean ice water content $\left(\mathrm{g} \mathrm{m}^{-3}\right)$

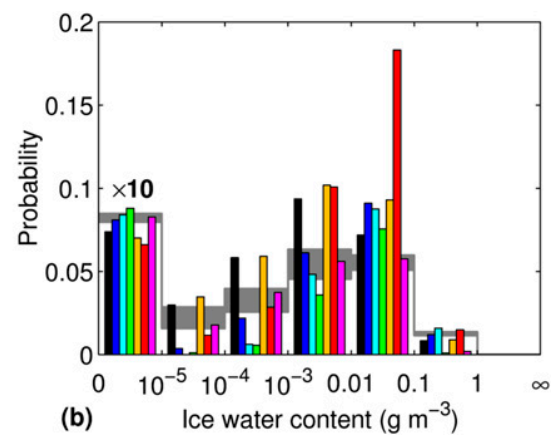

(b) Ice water content $\left(\mathrm{g} \mathrm{m}^{-3}\right)$

FIG. 29-10. (a) Mean IWC at the three Cloudnet observatories (CESAR, SIRTA, and CFARR) for the year 2004 from the observations and seven models. Two lines are shown for each model: the thick solid lines show the model after filtering to remove ice clouds too tenuous for the radar to detect, while the thin dashed lines are for all model clouds. The error bars indicate the uncertainty resulting from possible radar calibration errors and uncertainties in the mass-size relationship. (b) Corresponding histograms of observed and model IWC for clouds between 3- and 7-km altitude. Note that the bars in the lowest bin are shown at a tenth of their true height.

weather and climate models making the development and improvement of scale-adaptive parameterizations a necessity. Measurements obtained from permanent profiling sites can help to constrain these insufficiencies but require a framework that brings together simulations and observations in an appropriate manner. Neggers et al. (2012) developed such a platform, the KPT, where models and measurements can be evaluated and compared interactively. Here data streams from the CESAR site are used for evaluation of continuous single-column model (SCM) and LES runs at multiple time scales. In this way, both typical long-term model behavior and process-level case studies can be investigated. KPT proved its value by successfully identifying a compensating error between cloud vertical structure and cloud overlap (Neggers and Siebesma 2013). The test bed approach being at the interface of the observational and the modeling community helps to efficiently exploit observations for atmospheric model improvement. Currently the KPT is extended to the Integrated ScaleAdaptive Parameterization and Evaluation (InScAPE) project centered at the JOYCE observatory with the potential for transfer to further profiling sites (http://gop. meteo.uni-koeln.de/ neggers/InScAPE/).

\section{3) EUCLIPSE CMIP MODEL EVALUATIONS}

The EUCLIPSE project is a European collaborative effort, funded by the Seventh Framework Program of the European Commission, dedicated to improve the evaluation, understanding, and description of the role of clouds in Earth's climate. The central focus of the project is to reduce the uncertainty in the representation of cloud processes and feedbacks in the new generation of earth system models.
Cheruy et al. (2013) used the harmonized ECTD (presented in section 3b) to evaluate the standard and new parameterizations of boundary layer, convection, and clouds in the Earth System Model of L'Institut Pierre-Simon Laplace. Realistic coupling with the surface is an essential element of 3D simulations over a continental site. Hence two different land surface hydrology parameterizations were considered to analyze different land-atmosphere interactions. For this evaluation, the multiparameter characteristic of atmospheric profiling observatories is essential. It allows separate components of the system to be constrained simultaneously, such as radiative fluxes, latent and sensible heat fluxes, the height of the mixing layer, temperature and humidity in the boundary layer and in the soil, and properties of boundary layer clouds. Ten-year simulations of the coupled land surface-atmospheric modules were compared to observations collected at the SIRTA Observatory. Simulations were conducted with a stretched grid in the vicinity of the SIRTA Observatory, in a nudged mode to enable comparisons with observed parameters following a methodology developed by Coindreau et al. (2007). The study highlights how identified biases in temperature and humidity can be explained by biases in the partition between surface sensible and latent heat, by underestimation of boundary layer clouds, and insufficient turbulent transport in the surface layer. In addition, the approach allowed the authors to test how new parameterizations can reduce biases in the different components. Stegehuis et al. (2013) suggest that the partition between surface sensible and latent heat is of particular importance if climate prediction models are to correctly predict summertime heat waves over Europe. Campoy et al. (2013) suggest 

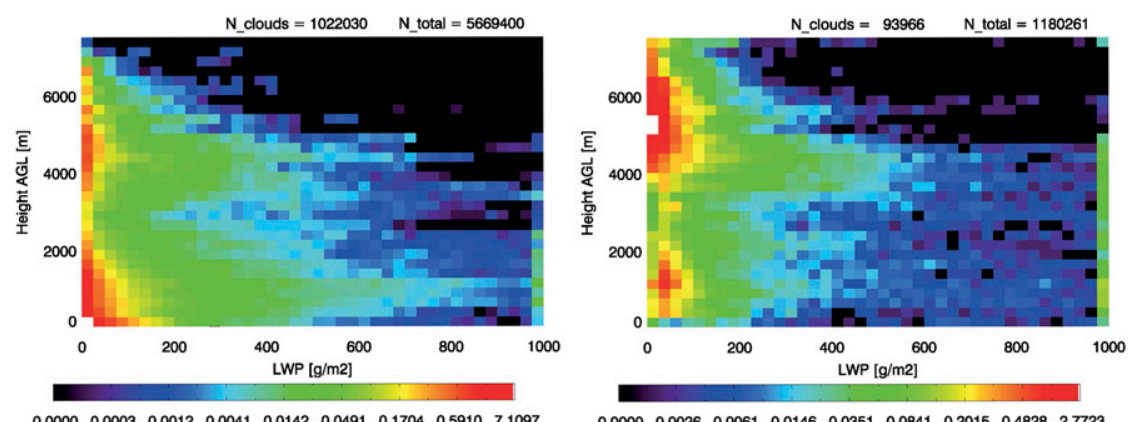

FIG. 29-11. Joint histogram of LWP and cloud-base height for 2006 for (left) Djougou and (right) Niamey.

that the description of groundwater in land surface models should be improved to obtain better predictions of summertime heat waves.

\section{Collaborations between U.S. ARM and EU programs}

The scientific programs, improvements in retrieval algorithm, extensive datasets, and efficient frameworks for model evaluations developed by European scientists, have triggered significant interest in the U.S. ARM scientific community. The conduct of observational field campaigns/experiments is an area where collaboration between the ARM and EU programs can be found. The participation of U.S. investigators in EU field campaigns was reinforced after the AMF was developed (section 4a). Collaborations between ARM and EU atmospheric profiling research observatories strengthened through the development of harmonized data interpretation algorithms (section 4b) and of model evaluation frameworks (section 4c). Common use of ARM-EU APRO datasets in scientific investigations is also an identified avenue of collaboration (section 4d). Collaboration was developed mostly outside any formal framework through bilateral collaboration between U.S. and EU scientists. These initiatives resulted in significant cross-fertilization between the ARM and EU programs.

\section{a. Common field campaigns}

To complement its permanent sites, the ARM Program developed the AMF to collect data in additional regions of interest to the general atmospheric science community (Miller et al. 2016, chapter 9). An open call for proposals for deployment periods of 6-12 months is issued each year. The European Community successfully applied twice to complement major field experiments with AMF proposals. The first AMF deployment occurred in Niamey, Niger, in 2006. In 2007, the AMF was deployed in the Black Forest, Germany.
The AMF deployment in Niamey $\left(13.5^{\circ} \mathrm{N}, 2.1^{\circ} \mathrm{E}\right)$ was associated with two large international campaigns: the African Monsoon Multidisciplinary Analysis (AMMA; Lebel et al. 2010) and the Geostationary Earth Radiation Budget (GERB; Harries et al. 2005) experiment. The proposal to the ARM Program leading to this deployment was titled Radiative Atmospheric Divergence Using the AMF, GERB Data, and AMMA Stations (RADAGAST). The proposal represented an international effort to measure continuously the radiative fluxes at the surface and top-of-the-atmosphere through the seasonal progression of the West African monsoon (Miller and Slingo 2007). Because precipitation in Niamey is limited to the monsoon period from June to September, a strong seasonality in the surface energy balance is obvious (Miller et al. 2009). The site is also well-suited to study the impact of Saharan dust, biomass burning, and deep convection.

The AMF deployment in Niamey was an integral part of the AMMA north-south transect that allowed the monsoon progression to be studied in detail. The most southern station Djougou, Benin $\left(9.6^{\circ} \mathrm{N}, 1.7^{\circ} \mathrm{E}\right)$, is under monsoon influence already in April, while the most northern station Gourma, Mali $\left(16.0^{\circ} \mathrm{N}, 1.5^{\circ} \mathrm{W}\right)$, becomes affected by moist air masses usually after June. Therefore annual precipitation in Djougou is much stronger ( $1124 \mathrm{~mm}$ in 2006) than in Niamey $(384 \mathrm{~mm})$. As shown in Fig. 29-11, the difference in low-level clouds is also quite pronounced with only few clouds bearing more than $200 \mathrm{~g} \mathrm{~m}^{-2}$ liquid water path in Niamey, while above Djougou such values typical for daytime boundary layer development are found much more frequently (Pospichal 2009). Both sites show the frequent occurrence of midlevel clouds located at the top of the Saharan air layer (Bouniol et al. 2012).

The Convective and Orographically Induced Precipitation Study (COPS; Wulfmeyer et al. 2011) in summer 2007 was motivated by the need to advance the quality of forecasts of orographically induced convective precipitation. To identify the physical and chemical 


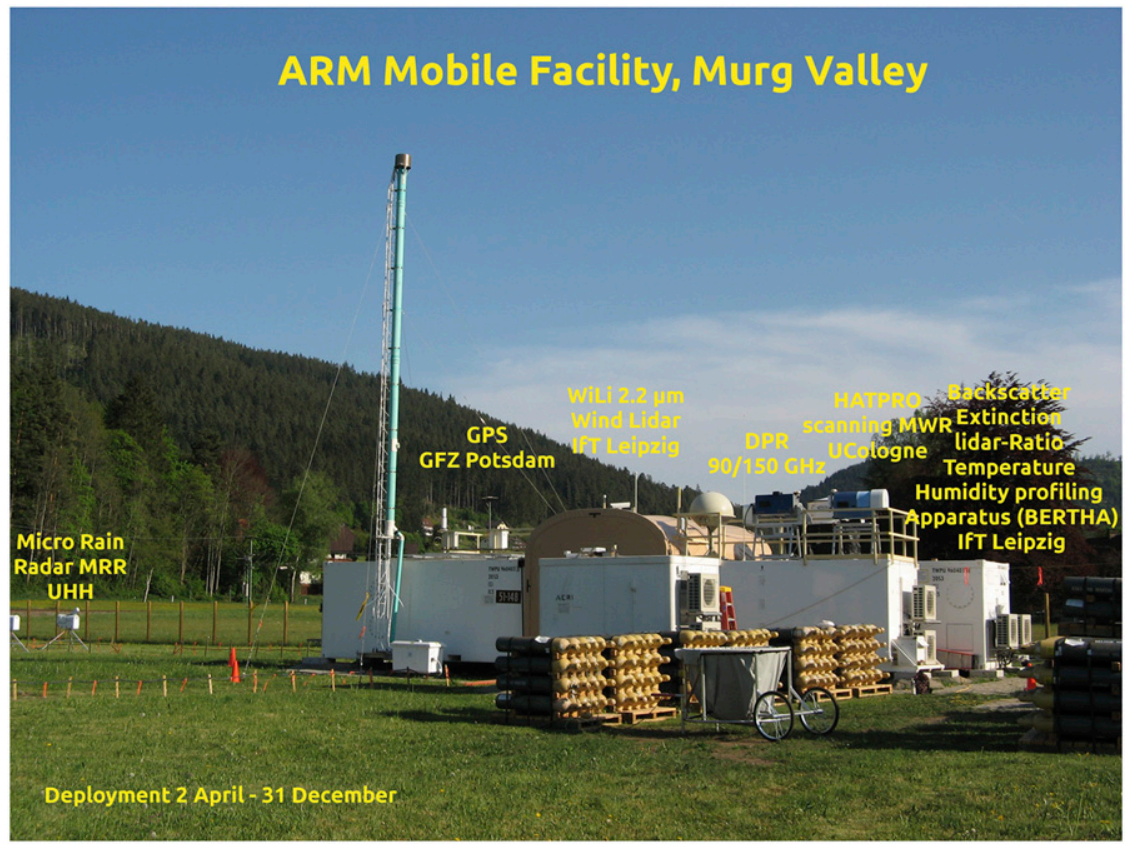

FIG. 29-12. ARM Mobile Facility deployment in the Murg Valley, Germany.

processes responsible for the forecast deficiencies, COPS combined 4D observations and high-resolution modeling in a strong international collaboration. In situ and remote sensing networks were installed in southwestern Germany, 10 research aircraft were operated, and a synergy of multiwavelength passive and active remote sensing instruments such as lidars, radars and radiometers were operated at five supersites. The AMF located in the Murg Valley (Fig. 29-12) was an integral part of the supersite transect across the Black Forest, the Rhine Valley, and the Vosges Mountains. The continuous measurements over the 9-month deployment period allowed long-term cloud statistics to be derived (Ebell et al. 2011) and supplemented the 37 COPS intensive operation days. The broad frequency coverage of microwave radiometers from ARM and European partners at the AMF also were exploited to improve the description of water vapor continuum absorption (Turner et al. 2009). The COPS special issue in the Quarterly Journal of the Royal Meteorological Society in January 2011 with 21 contributions nicely represents the breadth of activities including the effects of soil moisture, surface energy budget, convective initiation and enhancement, multiscale interactions, long-range dust transport, aerosol and cloud microphysics, data assimilation, and forecast studies.

In addition to the complete AMF deployments, ARM-EU collaborations also took place on smaller scales via less formal participation in field campaigns. One example is the second field experiment of the Radiative Heating in Underexplored Bands Campaigns
(RHUBC) project that took place in the Atacama Desert at $5300 \mathrm{~m}$ above sea level (Turner and Mlawer 2010). Here, the University of Cologne participated with a microwave radiometer to complement measurements across the full spectral range. In addition, the campaign demonstrated the superiority of more recent water vapor absorption models for climate simulations (Turner et al. 2012) and improved our knowledge in microwave calibration techniques (Maschwitz et al. 2013).

\section{b. ARM-EU collaboration on retrieval algorithm development}

Partly triggered by the activities of CLIWA-NET (section $2 \mathrm{~b}$ ), strong collaboration on microwave radiometry between ARM and EU scientists has been developed over more than a decade. In this period microwave radiometers developed from research instruments to operational tools for profiling atmospheric temperature and humidity and observing the columnar amount of liquid water. Scientists from ARM and EU have written reviews jointly on microwave radiometry (Westwater et al. 2005), worked on various processing challenges that affect the accuracy of the derived products, and participated in joint field experiments (see section $4 a$ ).

Maschwitz et al. (2013) assessed the different sources of uncertainty involved in the calibration of microwave radiometers. This includes the effects of antenna beamwidth, which is especially important for elevation scans used in the tipping curve calibration, as well as the impact of channel bandpass characteristics, which were investigated 
TABLE 29-13. Collaborative work on retrieval development.

\begin{tabular}{|c|c|c|}
\hline Topic & Details & References \\
\hline \multirow{3}{*}{ Microwave radiometer measurement uncertainty } & Calibration assessment & Maschwitz et al. (2013) \\
\hline & Liquid nitrogen calibration & Paine et al. (2014) \\
\hline & Instrument cross validation & Cimini et al. (2009) \\
\hline \multirow[t]{2}{*}{ Microwave absorption models } & Supercooled liquid water continuum water vapor & Kneifel et al. (2014) \\
\hline & absorption & Turner et al. $(2012,2009)$ \\
\hline \multirow[t]{2}{*}{ Microwave retrieval uncertainty } & Effect of instrument parameters & Meunier et al. (2013) \\
\hline & Uncertainty in ground truthing & Mattioli et al. (2008) \\
\hline Microwave retrieval of integrated quantities & $\begin{array}{l}\text { Integrated water vapor and liquid water for Arctic } \\
\text { observations }\end{array}$ & Cimini et al. (2007) \\
\hline Microwave thermodynamic profiling & $\begin{array}{l}\text { 1D VAR for continuous profiling of temperature } \\
\text { and humidity for } 2010 \text { Winter Olympics }\end{array}$ & Cimini et al. (2011) \\
\hline Infrared retrievals & $\begin{array}{l}\text { Uncertainty of thermodynamic profiles and cloud } \\
\text { properties }\end{array}$ & Turner and Löhnert (2014) \\
\hline Sensor synergy & $\begin{array}{l}\text { Uncertainty in the retrieval of cloud liquid water } \\
\text { from active and passive microwave } \\
\text { observations }\end{array}$ & Ebell et al. (2010) \\
\hline Sensor synergy & $\begin{array}{l}\text { Thermodynamic profile retrieval from combined } \\
\text { spectral microwave and infrared }\end{array}$ & Löhnert et al. (2009) \\
\hline Cloud profile retrieval & $\begin{array}{l}\text { Feasibility of liquid water profile retrieval from } \\
\text { passive microwave radiometer measurements }\end{array}$ & Crewell et al. (2009) \\
\hline
\end{tabular}

in detail by Meunier et al. (2013). In terms of converting measured brightness temperatures into geophysical products, the absorption characteristics of atmospheric gases and hydrometeors are important parameters for modeling the radiative transfer. Observations across the globe have been used in a collaborative effort (Turner et al. 2009; Kneifel et al. 2014) to test and further improve these models. In addition, the microwave observations were evaluated using different ground-truth data at profiling sites (Mattioli et al. 2008; Cimini. et al. 2009). Selected collaborative developments are presented in Table 29-13. To facilitate the exchange of information in the microwave radiometer user community the Microwave Radiometer Network (MWRNET) was established in 2009 by the EG-CLIMET COST action. The MWRNET connects people worldwide working with ground-based microwave radiometers to ultimately establish an operational network sharing knowledge, software, procedures, formats, and quality control. Collaboration with radar processing is starting first with work on Doppler spectra processing (Maahn and Kollias 2012) and formalizing information exchange.

\section{c. ARM-EU collaboration on model evaluation}

Following presentations of the Cloudnet radar-lidar analysis scheme and NWP model evaluation framework at ARM science team meetings, the Cloudnet scheme was included in the Fast Physics Testbed and Research (FASTER) project of the DOE Earth System Modeling (ESM) program that aims to evaluate and improve the fast-physics processes, particularly those associated with clouds, in various atmospheric models. The Cloudnet analysis scheme (see section 3a for a full description) was implemented on the observations from the various ARM sites worldwide, including the AMF at its numerous deployments. The Cloudnet model evaluation framework (described in section 3c) was implemented as an integral part of FASTER's Single Column Model Testbed (SCM-Testbed) and Numerical Weather Prediction Testbed (NWP-Testbed). In the SCM-Testbed, various SCMs are run over the ARM sites and compared to the observations. Since these models are very fast to run, it is straightforward to carry out reruns to test the impact of different physical parameterizations and to test how they affect the performance in terms of cloud properties.

In the NWP-Testbed, the performance of NWP models has been assessed in a much wider range of climate regimes and over longer periods compared to the original Cloudnet project. Figure 29-13 shows the time series of the symmetric extreme dependency score (SEDS) that gauges the skill of the various forecast models to predict cloud fraction above $5 \%$ in the right place at the right time. As discussed in section 3c, SEDS has the advantage over the traditional ETS that the value does not depend upon the frequency of the event. The skill scores for cloud fraction are plotted in Fig. 29-13a for the ARM SGP site from 2001 to 2010 and in Fig. 29-13b for the ARM Darwin site. Over the SGP site, the models show considerably higher skill in the winter than the summer, presumably because the location of convective clouds is more difficult to predict than clouds associated with wintertime synoptic disturbances. Also, all models show considerably higher skill than achieved by a 24-h persistence forecast. The picture is different over Darwin in Fig. 29-13b. While 

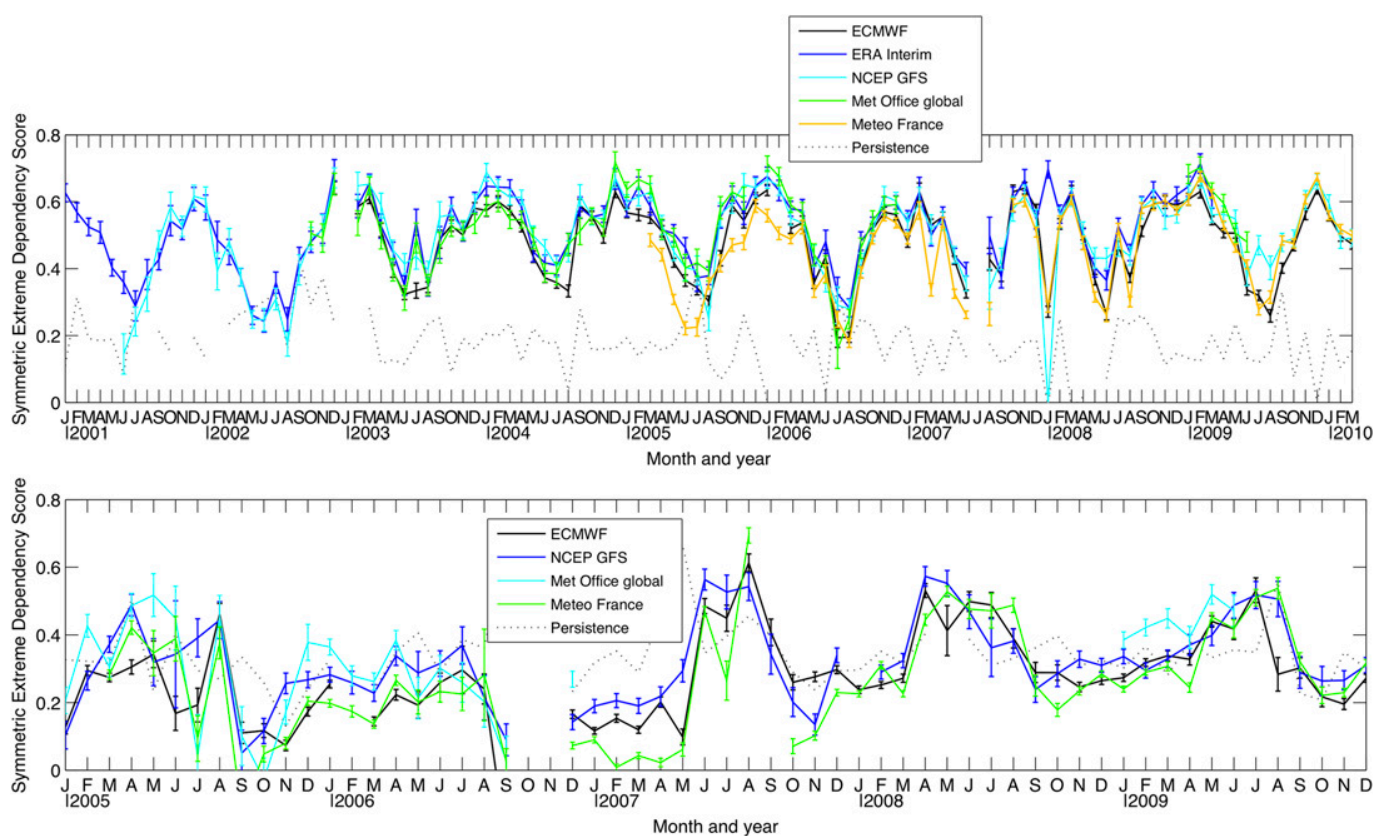

FIG. 29-13. The skill of various numerical weather prediction models in predicting cloud fraction greater than 0.05, as measured by the SEDS, for the (top) ARM SGP site 2001-10 and (bottom) Darwin site 2005-09. "Persistence" refers to using the observations from the previous $24 \mathrm{~h}$ as the prediction.

the models show generally more skill during the MayAugust peak of the dry season, there is considerably more year-to-year variability. Moreover, the challenge of tropical forecasting is highlighted by the fact that all models struggle to perform better than a persistence forecast at this location.

Having a decade of data makes it possible to determine whether cloud forecasts have improved in this period, but in order to account for natural variability in the predictability of weather systems from year to year, it is necessary to compare the skill to that from a reanalysis, in which the forecast system was kept constant. The reference in Fig. 29-13a is the ERA-Interim. Over this period, the NCEP, ECMWF, and Met Office forecasts appear to show no significant improvement relative to the reanalysis, in spite of the concerted research effort over recent years.

\section{d. Common use of ARM-EU data in scientific investigations}

A dozen publications are identified where EU-ARM collaboration was established to carry out algorithm developments, data validation, process studies, and other analyses using observations from both European APRO and ARM programs. A dozen, compared to several hundred publications using data from European APRO programs, and a similar number using ARM Program data, is a limited number. A review of the publications allows us to shed some light on the issue. The list of investigations and related keywords are presented in Table 29-14.
Nearly all first authors of these publications are principal investigators of European APRO programs. Hence they are all familiar with the European APRO data. All publications include coauthors who are principal investigators of the ARM Program or have been involved in a formal EU-ARM collaboration cited in this chapter. Hence these publications result from collaborations between authors who are familiar with the content and the benefits of both EU and ARM ground-based atmospheric profiling observations.

Half the publications rely on combined analyses of ground-based and satellite observations both for validation studies and for comprehensive process studies. Chepfer et al. (1999; 2000) and Naud et al. (2006) both evaluated retrievals of cloud properties (e.g., cloud altitude, cloud thermodynamic phase) from spaceborne passive radiometers using ground-based active remote sensors (e.g., cloud lidars and radars). Both used data from ARM (SGP and TWP) and Europe (CFARR, United Kingdom; SIRTA, France) to show if the uncertainties in satellite retrievals are site dependent. The use of multiple validation sites is particularly important to assess retrievals that are available globally. Pougatchev et al. (2007) developed a mathematical model to evaluate the contribution to bias and noise due to spatial mismatch between satellite and ground-based observations in intercomparison studies. They illustrated their model using ARM (SGP and TWP) and EU (MOL-RAO, Germany) radiosonde profiles. The A-Train CloudSat and CALIPSO 
TABLE 29-14. Scientific publications highlighting EU/U.S. collaborations using observations from both European APROs and U.S. ARM sites.

\begin{tabular}{|c|c|c|c|}
\hline Project framework (if relevant) & Reference & Key words & Observatories used \\
\hline $\begin{array}{l}\text { Polarization and Directionality } \\
\text { of Earth Reflectances } \\
\text { (POLDER) }\end{array}$ & $\begin{array}{l}\text { Chepfer et al. (1999) } \\
\text { Chepfer et al. (2000) }\end{array}$ & $\begin{array}{l}\text { Satellite validation, cloud altitude, } \\
\text { cloud phase, cirrus, ground- } \\
\text { based lidars }\end{array}$ & $\begin{array}{l}\text { ARM: SGP, TWP } \\
\text { EU: SIRTA }\end{array}$ \\
\hline \multirow[t]{2}{*}{$\begin{array}{l}\text { Along-Track Scanning } \\
\text { Radiometer (ATSR)-2 }\end{array}$} & Naud et al. (2006) & $\begin{array}{l}\text { Satellite validation, cloud-top al- } \\
\text { titude, ground-based radar }\end{array}$ & $\begin{array}{l}\text { ARM: SGP } \\
\text { EU: CFARR }\end{array}$ \\
\hline & Pougatchev et al. (2007) & $\begin{array}{l}\text { Satellite validation, bias and noise } \\
\text { in satellite retrieval, radiosonde } \\
\text { measurements }\end{array}$ & $\begin{array}{l}\text { ARM: SGP, TWP } \\
\text { EU: RAO }\end{array}$ \\
\hline \multirow[t]{2}{*}{ CloudSat } & Protat et al. (2009) & $\begin{array}{l}\text { Satellite validation, cloud base, } \\
\text { cloud top, cloud thickness, }\end{array}$ & $\begin{array}{l}\text { ARM: Darwin, AMF } \\
\text { (AMMA, COPS) }\end{array}$ \\
\hline & Protat et al. (2010) & $\begin{array}{l}\text { cloud reflectivity, cloud micro- } \\
\text { physics, ground-based cloud } \\
\text { radars }\end{array}$ & EU: SIRTA, RAO \\
\hline CloudSat & Protat et al. (2011) & $\begin{array}{l}\text { Calibration of ground-based } \\
\text { radars }\end{array}$ & $\begin{array}{l}\text { ARM: NSA } \\
\text { EU: CESAR }\end{array}$ \\
\hline CALIPSO & Dupont et al. (2010) & $\begin{array}{l}\text { Satellite validation, cloud base, } \\
\text { cloud top, cloud thickness, op- } \\
\text { tical depth, ground-based lidars }\end{array}$ & $\begin{array}{l}\text { ARM: SGP } \\
\text { EU: SIRTA } \\
\text { Other: Observatoire de } \\
\text { Haute Provence (OHP), } \\
\text { CERES Ocean Validation } \\
\text { Experiment (COVE) }\end{array}$ \\
\hline Cloudnet & van Zadelhoff et al. (2004) & $\begin{array}{l}\text { Retrieval of ice cloud properties, } \\
\text { ground-based radars }\end{array}$ & $\begin{array}{l}\text { ARM: SGP } \\
\text { EU: CFARR, CESAR }\end{array}$ \\
\hline \multirow[t]{2}{*}{ Cloudnet } & Hogan et al. (2005) & $\begin{array}{l}\text { Retrieval of cloud liquid water } \\
\text { content, ground-based radars }\end{array}$ & $\begin{array}{l}\text { ARM: SGP } \\
\text { EU: CFARR }\end{array}$ \\
\hline & Dupont et al. $(2008,2009)$ & $\begin{array}{l}\text { Cirrus cloud radiative effects, } \\
\text { broadband radiometers, GPS, } \\
\text { sunphotometers, lidars }\end{array}$ & $\begin{array}{l}\text { ARM: SGP, TWP, NSA } \\
\text { EU: SIRTA }\end{array}$ \\
\hline \multirow[t]{3}{*}{ COPS field experiment } & Ebell et al. (2011) & $\begin{array}{l}\text { Retrieval of cloud fraction, cloud } \\
\text { heights, cloud LWP, cloud } \\
\text { phase }\end{array}$ & $\begin{array}{l}\text { ARM: AMF (COPS) } \\
\text { EU: CFARR, CESAR }\end{array}$ \\
\hline & Naud et al. (2010) & $\begin{array}{l}\text { Vertical profiles of temperature } \\
\text { and cloud phase, GCM, ground- } \\
\text { based lidars }\end{array}$ & $\begin{array}{l}\text { ARM: SGP } \\
\text { EU: SIRTA }\end{array}$ \\
\hline & Tonttila et al. (2011) & $\begin{array}{l}\text { Cloud vertical velocity, AROME } \\
\text { mesoscale model, ground-based } \\
\text { radars }\end{array}$ & $\begin{array}{l}\text { ARM: SGP } \\
\text { EU: RAO }\end{array}$ \\
\hline
\end{tabular}

programs triggered numerous validations studies, among which a few relied on combined analyses of ARM and EU APRO data. Protat et al. (2009; 2011) assessed cloud-base height, top height, geometrical thickness, and reflectivity of ice clouds derived from CloudSat using airborne and five ground-based cloud radars (at ARM Darwin, EU MOL-RAO, and SIRTA observatories). They extended their investigation to evaluate retrievals of cloud microphysical properties (Protat et al. 2010). Dupont et al. (2010) assessed cloud-base height, top height, geometrical thickness, and optical depth of cirrus clouds from four midlatitude ground-based lidar datasets (at ARM SGP and EU SIRTA observatories). Later, Protat et al. (2011) showed that since the CloudSat cloud radar reflectivity had been calibrated using multiple references (Protat et al. 2009), the satellite cloud radar could be used in turn to calibrate cloud radars of the ground-based network that had not yet been intercalibrated [e.g., ARM North Slope of Alaska (NSA) and EU CESAR, the Netherlands].

Another topic of collaboration is the development of retrieval algorithms. Early work by van Zadelhoff et al. (2004) compared retrieval of ice cloud properties from radar measurements in the ARM Program and the EU Cloudnet program (see section $2 b$ ). They found that the relationships between radar reflectivity and ice water content were consistent between the European Union (CFARR and CESAR) and ARM SGP. However the relationship between radar reflectivity and droplet radius did not show such trans-Atlantic consistency. Hogan et al. (2005) showed that the liquid water content in stratocumulus can be retrieved by using the differential absorption between a $35-$ and a $94-\mathrm{GHz}$ radar. To prove the efficiency of the technique, the authors apply 
their method to dual radar datasets collected in both Europe (CFARR) and ARM SGP.

Several authors also use the multiprogram datasets to explore processes over different climate regions to study potential regional differences or to make their findings more universal if they are consistent at different locations. The added value of using multiprogram datasets is that authors can develop a complex analysis method that relies typically on multiple collocated observations and then apply this method on measurements from several observatories. This requires that the different observing programs offer consistent observing datasets. Several studies concern radiative effects of clouds. Dupont et al. (2009) investigated shortwave and longwave radiative effects of cirrus clouds using broadband radiometers, sun photometers, GPS, and lidars from EU SIRTA, SGP, TWP, and NSA. They showed that cloud radiative effects on surface shortwave and longwave irradiance varied greatly from the tropics to the midlatitudes and the Arctic. Ebell et al. (2011) investigated cloud properties and cloud radiative effects in a European mountain site using the AMF. They found that cloud liquid water path and radiative effects in the continental mountain site are significantly less than at EU CFARR and CESAR maritime site. Other authors used multiprogram datasets to study cloud processes in the observations and in atmospheric models, either climate models or numerical weather prediction models. Naud et al. (2010) used lidar and radiosonde measurements at ARM SGP and EU SIRTA observatories to study vertical profiles of temperature and their relationship to thermodynamic phase of optically thin cirrus. Tonttila et al. (2011) found significantly higher variability in observed cloud-base vertical velocity in ARM SGP and EU MOL-RAO data than in the Applications of Research to Operations at Mesoscale (AROME) mesoscale model.

We can conclude that there is a real motivation for carrying out investigations that rely on datasets developed by completely independent programs to expand the geographic coverage, to explore the validity of results across several locations (satellite and model evaluation), to explore process in different climate zones (process studies), to consolidate results (algorithm developments), and to prove the usefulness of the study. However, until now this has required significant skill, knowledge, and effort on the part of coauthors because EU and ARM APRO data are fully not harmonized. As datasets become more harmonized a larger number of publications can be expected to rely on multiple datasets.

\section{Outlook toward future collaborations}

Clouds, aerosol, and precipitation still pose key challenges for the prediction of future climate. Detailed ground-based profiling observations by APROs have unique potential to advance our understanding, but the full amount of information available across the globe is not fully exploited yet, as pointed out in section 4c. In November 2012, the Department of Energy Climate and Environmental Sciences Division hosted a joint workshop bringing together participants from the various European Union programs and the DOE Atmospheric Radiation Measurement Program to explore "Climate Change Challenges and Observations" (DOE-Climate and Environmental Sciences Division 2013). The workshop identified six outstanding science questions and discussed observation strategies to tackle them.

1) What is the distribution of aerosol properties for the Atmospheric Model Intercomparison Project period (i.e., since 1979)?

2) What is the coupling among microphysics, aerosols, and cloud dynamics as a function of scale and regime (e.g., vertical velocity or stability)?

3) How are precipitation, water vapor, and cloudiness coupled, and what roles does organization play in this coupling?

4) How do clouds and precipitation couple with surface properties?

5) What is the response of clouds to warming?

6) What is the response of the probability density function of precipitation to warming?

Clearly answering all questions would benefit from an enhanced collaboration between the EU and ARM communities. Within the discussions four collaboration topics emerged that are promising opportunities for joint activities.

\section{a. Collaboration topic 1: Retrieval algorithms and uncertainty}

Most importantly, the EU and ARM observing stations should develop integrated datasets with similar standards that are made available in a common location. These datasets should include both measured and retrieved atmospheric properties. For high-quality measurements, common methods for calibrating instruments must be developed-a good example is the already ongoing work on microwave radiometry within MWRNET (see section $4 \mathrm{~b}$ ). In response to the potential collaboration, a second workshop was organized to focus on retrieval algorithms and uncertainty. This workshop was held in May 2013 at the University of Cologne, Germany. There were 20 participants from both the ARM and EU partners. They discussed common algorithm frameworks and paths forward for improving and/or implementing and evaluating retrieval algorithms across EU and ARM observing stations. As a first step, a joint paper is being written to 
provide a general overview on retrieval algorithms and identifying important sources of uncertainty that need to be quantified in all retrieval algorithms (D. D. Turner et al. 2015, unpublished manuscipt).

\section{b. Collaboration topic 2: Field experiments and cruises}

Field campaigns like the $\mathrm{HD}(\mathrm{CP})^{2}$ Observational Prototype Experiment (HOPE) in April/May 2013 in Germany, the Biogenic Aerosols-Effects on Clouds and Climate (BAECC) in Hyytiälä (Finland) in 2014, and the Green Ocean Amazon experiment (GOAMAZON) in Brazil 2015 provide other opportunities for collaboration. The HOPE campaign that combined three profiling sites within less than a $10-\mathrm{km}$ range to investigate clouds at high resolution could serve as a test bed for LES models (see below) while the combination of airborne and ground-based observations seems promising for GOAMAZON. Bridging the Atlantic can be achieved by linking the atmospheric profiling site in Barbados (MPI Hamburg), the ARM site in the Azores, and transects of the Meteor and Polarstern research vessels. Future field campaigns, for example, Arctic sea ice study or clouds in the Southern Ocean, could benefit strongly from an early stage joint planning phase.

\section{c. Collaboration topic 3: Improving the link between models and observations}

The operational use of LES at profiling sites as done in the KPT (section 3c) is highly promising to match the scales of observations and models and should be made transferable to various sites. Model evaluation approaches developed in the United States and the European Union (section 3c) could be extended to include instrument simulators, for example, cloud radar simulators. For the larger-scale (see section $3 b$ ) a common observational dataset to be used for CMIP5 modeling evaluation should be developed.

\section{d. Collaboration topic 4: Standardization and organization}

On the more technical side, the architecture, standards, and framework for an integrated portal for metadata, products, and related information have been discussed. First steps have been taken already in terms of data integration between ACTRIS and ARM as a network of networks (section 2c). Aerosol profiles, water vapor, and liquid water will be the first geophysical parameters to test the full cycle from data harmonization via retrieval algorithms and uncertainty, value-added, and synthesis products.

Currently collaboration between the ARM Program and EU atmospheric observation programs rely on voluntary initiatives of motivated researchers in the United States and Europe. Coordination between U.S. and European funding agencies would be greatly beneficial to strengthen collaboration between the ARM Program and EU atmospheric observation programs. Such coordination would encourage the organization of common field campaigns and raise the level of scientific achievements. In addition, a bottom-up process building on mutual exchange visits by early career scientists, participation in summer schools, and sabbaticals has already proven to be efficient in enhancing scientific collaboration. European and U.S. researchers are ready for intensified collaborations in the future, which should be encouraged by both EU and ARM Programs.

Acknowledgments. The authors acknowledge the following people for their contributions and helpful remarks: Frank Beyrich, Sandrine Bony, Nico Cimini, Frédérique Cheruy, Volker Lehmann, Ulrich Löhnert, Sandip Pal, and Bernhard Pospichal. The financial support for EARLINET by the European Union under Grant RICA 025991 in the Sixth Framework Programme is gratefully acknowledged. Since 2011 EARLINET is integrated in the ACTRIS Research Infrastructure Project supported by the European Union Seventh Framework Programme (FP7/2007-2013) under Grant Agreement 262254. We also acknowledge the funding support within the research initiative High Definition Clouds and Precipitation for Climate Prediction $\mathrm{HD}(\mathrm{CP})^{2}$ (first phase 2012-16) by the German Ministry for Education and Research (BMBF).

\section{REFERENCES}

Ackerman, T. P., and G. M. Stokes, 2003: The Atmospheric Radiation Measurement Program. Phys. Today, 56, 3846, doi:10.1063/1.1554135.

Ansmann, A., M. Riebesell, and C. Weitkamp, 1990: Measurements of atmospheric aerosol extinction profiles with Raman lidar. Opt. Lett., 15, 746-748, doi:10.1364/OL.15.000746.

_ U. Wandinger, M. Riebesell, C. Weitkamp, and W. Michaelis, 1992: Independent measurement of extinction and backscatter profiles in cirrus clouds by using a combined Raman elasticbackscatter lidar. Appl. Opt., 31, 7113-7131, doi:10.1364/ AO.31.007113.

_ , and Coauthors, 2003: Long-range transport of Saharan dust to northern Europe: The 11-16 October 2001 outbreak with EARLINET. J. Geophys. Res., 108, 4783, doi:10.1029/ 2003JD003757.

- P. Seifert, M. Tesche, and U. Wandinger, 2012: Profiling of fine and coarse particle mass: Case studies of Saharan dust and Eyjafjallajökull/Grimsvötn volcanic plumes. Atmos. Chem. Phys., 12, 9399-9415, doi:10.5194/acp-12-9399-2012.

Balis, D., and Coauthors, 2003: Raman lidar and sunphotometric measurements of aerosol optical properties over Thessaloniki, Greece during a biomass burning episode. Atmos. Environ., 37, 4529-4538, doi:10.1016/S1352-2310(03)00581-8.

Barlow, J. F., T. M. Dunbar, E. G. Nemitz, C. R. Wood, M. W. Gallagher, F. Davies, E. O'Connor, and R. M. Harrison, 2011: 
Boundary layer dynamics over London, UK, as observed using Doppler lidar during REPARTEE-II. Atmos. Chem. Phys., 11, 2111-2125, doi:10.5194/acp-11-2111-2011.

Barrett, A. I., R. J. Hogan, and E. J. O'Connor, 2009: Evaluating forecasts of the evolution of the cloudy boundary layer using diurnal composites of radar and lidar observations. Geophys. Res. Lett., 36, L17811, doi:10.1029/2009GL038919.

Böckmann, C., and Coauthors, 2004: Aerosol lidar intercomparison in the framework of the EARLINET project. 2. Aerosol backscatter algorithms. Appl. Opt., 43, 977-989, doi:10.1364/ AO.43.000977.

—, D. Miranova, D. Müller, L. Scheidenbach, and R. Nessler, 2005: Microphysical aerosol parameters from multiwavelength lidar. J. Opt. Soc. Amer., 22, 518-528, doi:10.1364/ JOSAA.22.000518.

Boselli, A., R. Caggiano, C. Cornacchia, F. Madonna, M. Macchiato, L. Mona, G. Pappalardo, and S. Trippetta, 2012: Multi year sunphotometer measurements for aerosol characterization in a central Mediterranean site. Atmos. Res., 104, 98-110, doi:10.1016/ j.atmosres.2011.08.002.

Bouniol, D., and Coauthors, 2010: Using continuous ground-based radar and lidar measurements for evaluating the representation of clouds in four operational models. J. Appl. Meteor. Climatol., 49, 1971-1991, doi:10.1175/2010JAMC2333.1.

— , F. Couvreux, P. H. Kamsu-Tamo, M. Leplay, F. Guichard, F. Favot, and E. J. O'Connor, 2012: Diurnal and seasonal cycles of cloud occurrences, types, and radiative impact over West Africa. J. Appl. Meteor. Climatol., 51, 534-553, doi:10.1175/ JAMC-D-11-051.1.

Brandau, C. L., H. W. J. Russchenberg, and H. W. Knap, 2010: Evaluation of ground-based remotely sensed liquid water cloud properties using shortwave radiation measurements. Atmos. Res., 96, 366-377, doi:10.1016/j.atmosres.2010.01.009.

Browning, K. A., and Coauthors, 2007: The Convective Storm Initiation Project. Bull. Amer. Meteor. Soc., 88, 1939-1955, doi:10.1175/BAMS-88-12-1939.

Bühl, J., and Coauthors, 2013: LACROS: The Leipzig Aerosol and Cloud Remote Observations System. Remote Sensing of Clouds and the Atmosphere XVIII; and Optics in Atmospheric Propagation and Adaptive Systems XVI, A. Comeron et al., Eds., International Society for Optical Engineering (SPIE Proceedings, Vol. 8890), doi:10.1117/12.2030911.

Campoy, A., A. Ducharne, F. Chéruy, F. Hourdin, J. Polcher, and J. C. Dupont, 2013: Response of land surface fluxes and precipitation to different soil bottom hydrological conditions in a general circulation model. J. Geophys. Res. Atmos., 118, 10 725-10 739, doi:10.1002/jgrd.50627.

Carbone, R. E., and Coauthors, 2012: Thermodynamic Profiling Technologies Workshop report to the National Science Foundation and the National Weather Service. NCAR Tech. Note NCAR/TN-488+STR, 80 pp., doi:10.5065/D6SQ8XCF.

Chaikovsky, A., and Coauthors, 2012: Algorithm and software for the retrieval of vertical aerosol properties using combined lidar/radiometer data: Dissemination in EARLINET. Proc. 26th Int. Laser and Radar Conf., Vol. 1, Porto Heli, Greece, ICLAS/IRC, 399-402.

Chepfer, H., P. Goloub, L. Sauvage, P. H. Flamant, G. Brogniez, J. Spinhirne, M. Lavorato, and N. Sugimoto, 1999: Validation of POLDER/ADEOS data using a ground-based lidar network: Preliminary results for semi-transparent clouds. Phys. Chem. Earth, 24, 203-206, doi:10.1016/S1464-1909(98)00038-0.

, — - J. Spinhirne, P. H. Flamant, M. Lavorato, L. Sauvage, G. Brogniez, and J. Pelon, 2000: Cirrus cloud properties derived from POLDER-1/ADEOS polarized radiances: First validation using a ground-based lidar network. J. Appl. Meteor., 39, 154-168, doi:10.1175/1520-0450(2000)039<0154: CCPDFP $>2.0 . \mathrm{CO} ; 2$.

Cheruy, F., A. Campoy, J. C. Dupont, A. Ducharne, F. Hourdin, M. Haeffelin, M. Chiriaco, and A. Idelkadi, 2013: Combined influence of atmospheric physics and soil hydrology on the simulated meteorology at the SIRTA atmospheric observatory. Climate Dyn., 40, 2251-2269, doi:10.1007/ s00382-012-1469-y.

Chiriaco, M., S. Bastin, P. Yiou, M. Haeffelin, J. C. Dupont, and M. Stéfanon, 2014: European heatwave in July 2006: Observations and modeling showing how local processes amplify conducive large-scale conditions. Geophys. Res. Lett., 41, 5644-5652, doi:10.1002/2014GL060205.

Cimini, D., T. J. Hewison, L. Martin, J. Güldner, C. Gaffard, and F. S. Marzano, 2006: Temperature and humidity profile retrievals from ground-based microwave radiometers during TUC. Meteor. Z., 15, 45-56, doi:10.1127/0941-2948/2006/0099. , E. R. Westwater, A. J. Gasiewski, M. Klein, V. Leusky, and J. Liljegren, 2007: Ground-based millimeter- and submillimiterwave observations of low vapor and liquid water contents. IEEE Trans. Geosci. Remote Sens., 45, 2169-2180, doi:10.1109/ TGRS.2007.897450.

—, F. Nasir, E. R. Westwater, V. H. Payne, D. D. Turner, E. J. Milawer, M. L. Exner, and M. P. Cadeddu, 2009: Comparison of ground-based millimeter-wave observations and simulations in the Arctic winter. IEEE Trans. Geosci. Remote Sens., 47, 3098-3106, doi:10.1109/TGRS.2009.2020743.

- and Coauthors, 2011: Thermodynamic atmospheric profiling during the 2010 Winter Olympics using ground-based microwave radiometry. IEEE Trans. Geosci. Remote Sens., 49, 4959-4969, doi:10.1109/TGRS.2011.2154337.

—, F. De Angelis, J. C. Dupont, S. Pal, and M. Haeffelin, 2013: Mixing layer height retrievals by multichannel microwave radiometer observations. Atmos. Meas. Tech., 6, 2941-2951, doi:10.5194/amt-6-2941-2013.

Coindreau, O., F. Hourdin, M. Haeffelin, A. Mathieu, and C. Rio, 2007: Assessment of physical parameterizations using a global climate model with stretchable grid and nudging. Mon. Wea. Rev., 135, 1474-1489, doi:10.1175/MWR3338.1.

Cress, T. S., and D. L. Sisterson, 2016: Deploying the ARM sites and supporting infrastructure. The Atmospheric Radiation Measurement (ARM) Program: The First 20 Years, Meteor. Monogr., No. 57, Amer. Meteor. Soc., doi:10.1175/ AMSMONOGRAPHS-D-15-0049.1.

Crewell, S., and Coauthors, 2004: The BALTEX Bridge Campaign: An integrated approach for a better understanding of clouds. Bull. Amer. Meteor. Soc., 85, 1565-1584, doi:10.1175/ BAMS-85-10-1565.

— K. K. Ebell, U. Löhnert, and D. D. Turner, 2009: Can liquid water profiles be retrieved from passive microwave zenith observations? Geophys. Res. Lett., 36, L06803, doi:10.1029/ 2008GL036934.

Dacre, H. F., and Coauthors, 2011: Evaluating the structure and magnitude of the ash plume during the initial phase of the 2010 Eyjafjallajokull eruption using lidar observations and NAME simulations. J. Geophys. Res., 116, D00U03, doi:10.1029/ 2011JD015608.

Defazio, D., A. Lockett, and M. Wright, 2009: Funding incentives, collaborative dynamics and scientific productivity: Evidence from the EU framework program. Res. Policy, 38, 293-305, doi:10.1016/j.respol.2008.11.008. 
DOE-Climate and Environmental Sciences Division, 2013: Biological and environmental research. U.S./European Workshop on Climate Change Challenges and Observations, U.S. Department of Energy Office of Science Rep. DOE/SC-0154, 40 pp. [Available online at http://science.energy.gov/ /media/ ber/pdf/CESD_EUworkshop_report.pdf.]

Donovan, D. P., and A. Apituley, 2013: Practical depolarizationratio-based inversion procedure: Lidar measurements of the Eyjafjallajokull ash cloud over the Netherlands. Appl. Opt., 52, 2394-2415, doi:10.1364/AO.52.002394.

Dufresne, J. L., and S. Bony, 2008: An assessment of the primary sources of spread of global warming estimates from coupled atmosphere-ocean models. J. Climate, 21, 5135-5144, doi:10.1175/ 2008JCLI2239.1.

Dupont, J.-C., and M. Haeffelin, 2008: Observed instantaneous cirrus radiative effect on surface-level shortwave and longwave irradiances. J. Geophys. Res., 113, D21202, doi:10.1029/ 2008JD009838.

,-- , and C. N. Long, 2008: Evaluation of cloudless-sky periods detected by shortwave and longwave algorithms using lidar measurements. Geophys. Res. Lett., 35, L10815, doi:10.1029/2008GL033658.

,-- , and,- 2009 : Cirrus cloud radiative effect on surfacelevel shortwave and longwave irradiances at regional and global scale. Atmos. Chem. Phys. Discuss., 9, 26777-26832, doi:10.5194/acpd-9-26777-2009.

_ and Coauthors, 2010: Macrophysical and optical properties of midlatitude high-altitude clouds from four ground-based lidars and collocated CALIOP observations. J. Geophys. Res., 115, D00H24, doi:10.1029/2009JD011943.

—, M. Haeffelin, A. Protat, D. Bouniol, N. Boyouk, and Y. Morille, 2012: Stratus fog formation and dissipation: A 6-day case study. Bound.-Layer Meteor., 143, 207-225, doi:10.1007/ s10546-012-9699-4.

Ebell, K., U. Löhnert, S. Crewell, and D. Turner, 2010: On characterizing the error in a remotely sensed liquid water content profile. Atmos. Res., 98, 57-68, doi:10.1016/j.atmosres.2010.06.002.

— S. Crewell, U. Löhnert, D. Turner, and E. O'Connor, 2011: Cloud statistics and cloud radiative effect for a low mountain site. Quart. J. Roy. Meteor. Soc., 137, 306-324, doi:10.1002/qj.748.

Emeis, S., K. Schäfer, and C. Münkel, 2008: Surface-based remote sensing of the mixing-layer height-A review. Meteor. Z., 17, 621-630, doi:10.1127/0941-2948/2008/0312.

Engelbart, D. A. M., and H. Steinhagen, 2001: Ground-based remote sensing of atmospheric parameters using integrated profiling stations. Phys. Chem. Earth, 26B, 219-223.

— W. A. Monna, J. Nash, and C. Matzler, 2009: Integrated ground-based remote sensing stations for atmospheric profiling. Earth System Science and Environmental Management (ESSEM), COST Action 720. [Available online at www.cost.eu/ domains_actions/essem/Actions/720.]

Fassò, A., R. Ignaccolo, F. Madonna, B. B. Demoz, and M. FrancoVilloria, 2014: Statistical modelling of collocation uncertainty in atmospheric thermodynamic profiles. Atmos. Meas. Tech., 7, 1803-1816, doi:10.5194/amt-7-1803-2014.

Fisher, B. E. A., et al., Eds., 1998: Harmonisation of the preprocessing of meteorological data for atmospheric dispersion models. Office for Official Publications of the European Communities, Earth System Science and Environmental Management (ESSEM), COST Action 710, 431 pp.

_ J. Kukkonen, and M. Schatzmann, 2001: Meteorology applied to urban air pollution problems: COST 715. Int. J. Environ. Pollut., 16, 560-570, doi:10.1504/IJEP.2001.000650.
Flentje, H., B. Heese, J. Reichardt, and W. Thomas, 2010: Aerosol profiling using the ceilometer network of the German Meteorological Service. Atmos. Meas. Tech. Discuss., 3, 3643-3673, doi:10.5194/amtd-3-3643-2010.

Forster, P., and Coauthors, 2007: Changes in atmospheric constituents and in radiative forcing. Climate Change 2007: The Physical Science Basis, S. Solomon et al., Eds., Cambridge University Press, 129-234.

Freutel, F., and Coauthors, 2013: Aerosol particle measurements at three stationary sites in the megacity of Paris during summer 2009: Meteorology and air mass origin dominate aerosol particle composition and size distribution. Atmos. Chem. Phys., 13, 933-959, doi:10.5194/acp-13-933-2013.

Gasteiger, J., S. Groß, V. Freudenthaler, and M. Wiegner, 2011: Volcanic ash from Iceland over Munich: Mass concentration retrieved from ground-based remote sensing measurements. Atmos. Chem. Phys., 11, 2209-2223, doi:10.5194/ acp-11-2209-2011.

Guibert, S., and Coauthors, 2005: The vertical distribution of aerosol over Europe: Synthesis of one year of EARLINET aerosol lidar measurements and aerosol transport modeling with LMDzT-INCA. Atmos. Environ., 39, 2933-2943, doi:10.1016/j.atmosenv.2004.12.046.

Güldner, J., and D. Spänkuch, 2001: Remote sensing of the thermodynamic state of the atmospheric boundary layer by ground-based microwave radiometry. J. Atmos. Oceanic Technol., 18, 925-933, doi:10.1175/1520-0426(2001)018<0925: RSOTTS $>2.0 . \mathrm{CO} ; 2$.

Haeffelin, M., and Coauthors, 2005: SIRTA, a ground-based atmospheric observatory for cloud and aerosol research. Ann. Geophys., 23, 253-275, doi:10.5194/angeo-23-253-2005.

_ , and Coauthors, 2010: PARISFOG: Shedding new light on fog physical processes. Bull. Amer. Meteor. Soc., 91, 767-783, doi:10.1175/2009BAMS2671.1.

_ , and Coauthors, 2012: Evaluation of mixing height retrievals from automatic profiling lidars and ceilometers in view of future integrated networks in Europe. Bound.-Layer Meteor., 143, 49-75, doi:10.1007/s10546-011-9643-z.

— J. C. Dupont, N. Boyouk, D. Baumgardner, L. Gomes, G. Roberts, and T. Elias, 2013: A comparative study of radiation fog and quasi-fog formation processes during the ParisFog Field Experiment 2007. Pure Appl. Geophys., 170, 2283-2303, doi:10.1007/s00024-013-0672-z.

Hall, M. P. M., J. W. F. Goddard, and S. M. Cherry, 1984: Identification of hydrometeors and other targets by dual-polarization radar. Radio Sci., 19, 132-140, doi:10.1029/RS019i001p00132.

Harries, J. E., and Coauthors, 2005: The Geostationary Earth Radiation Budget (GERB) experiment. Bull. Amer. Meteor. Soc., 86, 945-960, doi:10.1175/BAMS-86-7-945.

Harvey, N. J., R. J. Hogan, and H. F. Dacre, 2013: A method to diagnose boundary-layer type using Doppler lidar. Quart. J. Roy. Meteor. Soc., 139, 1681-1693, doi:10.1002/qj.2068.

Heese, B., H. Flentje, D. Althausen, A. Ansmann, and S. Frey, 2010: Ceilometer lidar comparison: Backscatter coefficient retrieval and signal-to-noise ratio determination. Atmos. Meas. Tech., 3, 1763-1770, doi:10.5194/amt-3-1763-2010.

Hewison, T., 2007: 1D-VAR retrievals of temperature and humidity profiles from a ground-based microwave radiometer. IEEE Trans. Geosci. Remote Sens., 45, 2163-2168, doi:10.1109/ TGRS.2007.898091.

Hogan, R. J., and A. J. Illingworth, 2000: Deriving cloud overlap statistics from radar. Quart. J. Roy. Meteor. Soc., 126, $2903-$ 2909, doi:10.1002/qj.49712656914. 
- , and —_, 2003: Parameterizing ice cloud inhomogeneity and the overlap of inhomogeneities using cloud radar data. J. Atmos. Sci., 60, 756-767, doi:10.1175/1520-0469(2003)060<0756: PICIAT $>2.0 . \mathrm{CO} ; 2$.

- D. Bouniol, D. N. Ladd, E. J. O'Connor, and A. J. Illingworth, 2003a: Absolute calibration of 94/95-GHz radars using rain. J. Atmos. Oceanic Technol., 20, 572-580, doi:10.1175/1520-0426(2003)20<572:ACOGRU>2.0.CO;2.

- P. N. Francis, H. Flentje, A. J. Illingworth, M. Quante, and J. Pelon, 2003b: Characteristics of mixed-phase clouds. I: Lidar, radar and aircraft observations from CLARE'98. Quart. J. Roy. Meteor. Soc., 129, 2089-2116, doi:10.1256/rj.01.208.

_- N. Gaussiat, and A. J. Illingworth, 2005: Stratocumulus liquid water content from dual-wavelength radar. J. Atmos. Oceanic Technol., 22, 1207-1218, doi:10.1175/JTECH1768.1.

— M. P. Mittermaier, and A. J. Illingworth, 2006: The retrieval of ice water content from radar reflectivity factor and temperature and its use in the evaluation of a mesoscale model. J. Appl. Meteor. Climatol., 45, 301-317, doi:10.1175/JAM2340.1.

— E. E. O'Connor, and A. J. Illingworth, 2009a: Verification of cloud-fraction forecasts. Quart. J. Roy. Meteor. Soc., 135, 1494-1511, doi:10.1002/qj.481.

— A. L. M. Grant, A. J. Illingworth, G. N. Pearson, and E. J. O'Connor, 2009b: Vertical velocity variance and skewness in clear and cloud-topped boundary layers as revealed by Doppler lidar. Quart. J. Roy. Meteor. Soc., 135, 635-643, doi:10.1002/qj.413.

—, C. A. T. Ferro, I. T. Jolliffe, and D. B. Stephenson, 2010: Equitability revisited: Why the "equitable threat score" is not equitable. Wea. Forecasting, 25, 710-726, doi:10.1175/ 2009WAF2222350.1.

Holben, B. N., and Coauthors, 1998: AERONET-A federated instrument network and data archive for aerosol characterization. Remote Sens. Environ., 66, 1-16, doi:10.1016/ S0034-4257(98)00031-5.

Illingworth, A. J., and Coauthors, 2007: Cloudnet: Continuous evaluation of cloud profiles in seven operational models using ground-based observations. Bull. Amer. Meteor. Soc., 88, 883898, doi:10.1175/BAMS-88-6-883.

Kadygrov, E. N., and D. R. Pick, 1998: The potential for temperature retrieval from an angular-scanning single-channel microwave radiometer and some comparison with in situ observation. Appl. Meteor., 5, 393-404, doi:10.1017/S1350482798001054.

Kalthoff, N., and Coauthors, 2013: KITcube-A mobile observation platform for convection studies deployed during HyMeX. Meteor. Z., 22, 633-647, doi:10.1127/0941-2948/2013/0542.

Kneifel, S., S. Redl, E. Orlandi, U. Löhnert, M. P. Cadeddu, D. D. Turner, and M.-T. Chen, 2014: Absorption properties of supercooled liquid water between 31 and $225 \mathrm{GHz}$ : Evaluation of absorption models using ground-based observations. J. Appl. Meteor. Climatol., 53, 1028-1045, doi:10.1175/JAMC-D-13-0214.1.

Lebel, T., and Coauthors, 2010: The AMMA field campaigns: Multiscale and multidisciplinary observations in the West African region. Quart. J. Roy. Meteor. Soc., 136, doi:10.1002/qj.486.

Löhnert, U., and O. Maier, 2012: Operational profiling of temperature using ground-based microwave radiometry at Payerne: Prospects and challenges. Atmos. Meas. Tech., 5, 1121-1134, doi:10.5194/amt-5-1121-2012.

_ - S. Crewell, and C. Simmer, 2004: An integrated approach toward retrieving physically consistent profiles of temperature, humidity, and cloud liquid water. J. Appl. Meteor., 43, 1295-1307, doi:10.1175/1520-0450(2004)043<1295: AIATRP $>2.0 . C O ; 2$.
, O. Krasnov, E. J. O'Connor, and H. W. J. Russchenberg, 2008: Advances in continuously profiling the thermodynamic state of the boundary layer: Integration of measurements and methods. J. Atmos. Oceanic Technol., 25, 1251-1266, doi:10.1175/ 2007JTECHA961.1.

, D. Turner, and S. Crewell, 2009: Ground-based temperature and humidity profiling using spectral infrared and microwave observations. Part I: Simulated retrieval performance in clear sky conditions. J. Appl. Meteor. Climatol., 48, 1017-1032, doi:10.1175/2008JAMC2060.1.

_ S. Kneifel, A. Battaglia, M. Hagen, L. Hirsch, and S. Crewell, 2011: A multisensor approach toward a better understanding of snowfall microphysics: The TOSCA project. Bull. Amer. Meteor. Soc., 92, 613-628, doi:10.1175/2010BAMS2909.1.

- and Coauthors, 2014: JOYCE: Jülich Observatory for Cloud Evolution. Bull. Amer. Meteor. Soc., 96, 1157-1174, doi:10.1175/ BAMS-D-14-00105.1.

Long, C. N., T. P. Ackerman, K. L. Gaustad, and J. N. S. Cole, 2006: Estimation of fractional sky cover from broadband shortwave radiometer measurements. J. Geophys. Res., 111, D11204, doi:10.1029/2005JD006475.

Lopatin, A., O. Dubovik, A. Chaikovsky, P. Goloub, T. Lapyonok, D. Tanré, and P. Litvinov, 2013: Enhancement of aerosol characterization using synergy of lidar and sun-photometer coincident observations: The GARRLiC algorithm. Atmos. Meas. Tech., 6, 2065-2088, doi:10.5194/amt-6-2065-2013.

Maahn, M., and P. Kollias, 2012: Improved micro rain radar snow measurements using Doppler spectra post-processing. Atmos. Meas. Tech., 5, 2661-2673, doi:10.5194/amt-5-2661-2012.

Madonna, F., A. Amodeo, G. D'Amico, L. Mona, and G. Pappalardo, 2010: Observation of non-spherical ultragiant aerosol using a microwave radar. Geophys. Res. Lett., 37, L21814, doi:10.1029/ 2010 GL044999.

— , and Coauthors, 2011: CIAO: The CNR-IMAA advanced observatory for atmospheric research. Atmos. Meas. Tech., 4, 1191-1208, doi:10.5194/amt-4-1191-2011.

— A. Amodeo, G. D'Amico, and G. Pappalardo, 2013: A study on the use of radar and lidar for characterizing ultragiant aerosol. J. Geophys. Res. Atmos., 118, 10 056-10 071, doi:10.1002/ jgrd.50789.

, M. Rosoldi, J. Güldner, A. Haefele, R. Kivi, M. P. Cadeddu, D. Sisterson, and G. Pappalardo, 2014: Quantifying the value of redundant measurements at GCOS Reference Upper-Air Network sites. Atmos. Meas. Tech. Discuss., 7, 6327-6357, doi:10.5194/amtd-7-6327-2014.

Markowicz, K. M., P. J. Flatau, A. E. Kardas, J. Remiszewska, K. Stelmaszczyk, and L. Woeste, 2008: Ceilometer retrieval of the boundary layer vertical aerosol extinction structure. J. Atmos. Oceanic Technol., 25, 928-944, doi:10.1175/ 2007JTECHA1016.1.

Martin, S., F. Beyrich, and J. Bange, 2014: Observing entrainment processes using a small unmanned aerial vehicle: A feasibility study. Bound.-Layer Meteor., 150, 449-467, doi:10.1007/ s10546-013-9880-4.

Martucci, G., and C. D. O'Dowd, 2011: Ground-based retrieval of continental and marine warm cloud microphysics. Atmos. Meas. Tech., 4, 2749-2765, doi:10.5194/amt-4-2749-2011.

_ J. Ovadnevaite, D. Ceburnis, H. Berresheim, S. Varghese, D. Martin, R. Flanagan, and C. D. O'Dowd, 2012: Impact of volcanic ash plume aerosol on cloud microphysics. Atmos. Environ., 48, 205-218, doi:10.1016/j.atmosenv.2011.12.033.

Maschwitz, G., U. Löhnert, S. Crewell, T. Rose, and D. D. Turner, 2013: Investigation of ground-based microwave radiometer 
calibration techniques at $530 \mathrm{hPa}$. Atmos. Meas. Tech., 6, 26412658, doi:10.5194/amt-6-2641-2013.

Matthias, V., and Coauthors, 2004a: Vertical aerosol distribution over Europe: Statistical analysis of Raman lidar data from 10 European Aerosol Research Lidar Network (EARLINET) stations. J. Geophys. Res., 109, D18201, doi:10.1029/ 2004JD004638.

— framework of the EARLINET Project. 1. Instruments. Appl. Opt., 43, 961-976, doi:10.1364/AO.43.000961.

Mattioli, V., E. R. Westwater, D. Cimini, A. J. Gasiewski, M. Klein, and V. Y. Leuski, 2008: Microwave and millimeter-wave radiometric and radiosonde observations in an Arctic environment. J. Atmos. Oceanic Technol., 25, 1768-1777, doi:10.1175/ 2008JTECHA1078.1.

Meier, J., and Coauthors, 2012: A regional model of European aerosol transport: Evaluation with sun photometer, lidar and air quality data. Atmos. Environ., 47, 519-532, doi:10.1016/ j.atmosenv.2011.09.029.

Meunier, V., U. Löhnert, P. Kollias, and S. Crewell, 2013: Biases caused by the instrument bandwidth and beam width on simulated brightness temperature measurements from scanning microwave radiometers. Atmos. Meas. Tech., 6, 1171-1187, doi:10.5194/amt-6-1171-2013.

Miller, M., and A. Slingo, 2007: The ARM Mobile Facility and its first international deployment: Measuring radiative flux divergence in West Africa. Bull. Amer. Meteor. Soc., 88, 12291244, doi:10.1175/BAMS-88-8-1229.

Miller, M. A., K. Nitschke, T. P. Ackerman, W. R. Ferrell, N. Hickmon, and M. Ivey, 2016: The ARM Mobile Facilities. The Atmospheric Radiation Measurement (ARM) Program: The First 20 Years, Meteor. Monogr., No. 57, Amer. Meteor. Soc., doi:10.1175/AMSMONOGRAPHS-D-15-0051.1.

Miller, R. L., A. Slingo, J. C. Barnard, and E. Kassianov, 2009: Seasonal contrast in the surface energy balance of the Sahel. J. Geophys. Res., 114, D00E05, doi:10.1029/2008JD010521.

Mona, L., A. Amodeo, M. Pandolfi, and G. Pappalardo, 2006: Saharan dust intrusions in the Mediterranean area: Three years of Raman lidar measurements. J. Geophys. Res., 111, D16203, doi:10.1029/2005JD006569.

_ , and Coauthors, 2007: Characterization of the variability of the humidity and cloud fields as observed from a cluster of ground-based lidar systems. Quart. J. Roy. Meteor. Soc., 133, 257-271, doi:10.1002/qj.160.

— , and Coauthors, 2009: One year of CNR-IMAA multiwavelength Raman lidar measurements in correspondence of CALIPSO overpass: Level 1 products comparison. Atmos. Chem. Phys., 9, 7213-7228, doi:10.5194/acp-9-7213-2009.

—- A. Amodeo, G. D'Amico, A. Giunta, F. Madonna, and G. Pappalardo, 2012: Multi-wavelength Raman lidar observations of the Eyjafjallajökull volcanic cloud over Potenza, southern Italy. Atmos. Chem. Phys., 12, 2229-2244, doi:10.5194/ acp-12-2229-2012.

Morille, Y., M. Haeffelin, P. Drobinski, and J. Pelon, 2007: STRAT: An automated algorithm to retrieve the vertical structure of the atmosphere from single-channel lidar data. J. Atmos. Ocean. Technol., 24, 761-775, doi: 10.1175/JTECH2008.1.

Müller, D., U. Wandinger, and A. Ansmann, 1999: Microphysical particle parameters from extinction and backscatter lidar data by inversion with regularization: Theory. Appl. Opt., 38, 23462357, doi:10.1364/AO.38.002346.

_ I. Mattis, A. Ansmann, B. Wehner, D. Althausen, U. Wandinger, and O. Dubovik, 2004: Closure study on optical and microphysical properties of a mixed urban and Arctic haze air mass observed with Raman lidar and Sun photometer. J. Geophys. Res., 109, D13206, doi:10.1029/2003JD004200.

,,,--- U. Wandinger, C. Ritter, and D. Kaiser, 2007: Multiwavelength Raman lidar observations of particle growth during long-range transport of forest-fire smoke in the free troposphere. Geophys. Res. Lett., 34, L05803, doi:10.1029/2006GL027936.

Naud, C., J. P. Muller, and E. E. Clothiaux, 2006: Assessment of multispectral ATSR2 stereo cloud-top height retrievals. Remote Sens. Environ., 104, 337-345, doi:10.1016/j.rse.2006.05.008.

_ , and Coauthors, 2010: Thermodynamic phase profiles of optically thin midlatitude clouds and their relation to temperature. J. Geophys. Res., 115, D11202, doi:10.1029/2009JD012889.

Neggers, R. A. J., and A. P. Siebesma, 2013: Constraining a system of interacting parameterizations through multiple-parameter evaluation: Tracing a compensating error between cloud vertical structure and cloud overlap. J. Climate, 26, 6698-6715, doi:10.1175/JCLI-D-12-00779.1.

,-- , and T. Heus, 2012: Continuous single-column model evaluation at a permanent meteorological supersite. Bull. Amer. Meteor. Soc., 93, 1389-1400, doi:10.1175/BAMS-D-11-00162.1.

Neisser, J., W. Adam, F. Beyrich, U. Leiterer, and H. Steinhagen, 2002: Atmospheric boundary layer monitoring at the Meteorological Observatory Lindenberg as a part of the "Lindenberg Column": Facilities and selected results. Meteor. Z., 11, 241-253, doi:10.1127/0941-2948/2002/0011-0241.

O'Connor, E. J., A. J. Illingworth, and R. J. Hogan, 2004: A technique for autocalibration of cloud lidar. J. Atmos. Oceanic Technol., 21, 777-786, doi:10.1175/1520-0426(2004)021<0777: ATFAOC $>2.0 . \mathrm{CO} ; 2$.

_, R. J. Hogan, and A. J. Illingworth, 2005: Retrieving stratocumulus drizzle parameters using Doppler radar and lidar. J. Appl. Meteor., 44, 14-27, doi:10.1175/JAM-2181.1.

—, A. J. Illingworth, I. M. Brooks, C. D. Westbrook, R. J. Hogan, F. Davies, and B. J. Brooks, 2010: A method for estimating the turbulent kinetic energy dissipation rate from a vertically pointing Doppler lidar, and independent evaluation from balloon-borne in situ measurements. J. Atmos. Oceanic Technol., 27, 1652-1664, doi:10.1175/2010JTECHA1455.1.

Paine, S., D. D. Turner, and N. Küchler, 2014: Understanding thermal drift in liquid nitrogen loads used for radiometric calibration in the field. J. Atmos. Oceanic Technol., 31, 647655, doi:10.1175/JTECH-D-13-00171.1.

Pal, S., M. Haeffelin, and E. Batchvarova, 2013: Exploring a geophysical process-based attribution technique for the determination of the atmospheric boundary layer depth using aerosol lidar and near-surface meteorological measurements. J. Geophys. Res. Atmos., 118, 9277-9295, doi:10.1002/jgrd.50710.

Papayannis, A., and Coauthors, 2008: Systematic lidar observations of Saharan dust over Europe in the frame of EARLINET (20002002). J. Geophys. Res., 113, D10204, doi:10.1029/2007JD009028.

Pappalardo, G., and Coauthors, 2004: Aerosol lidar intercomparison in the framework of the EARLINET project. 3. Raman lidar algorithm for aerosol extinction, backscatter and lidar ratio. Appl. Opt., 43, 5370-5385, doi:10.1364/AO.43.005370.

— , and Coauthors, 2010: EARLINET correlative measurements for CALIPSO: First intercomparison results. J. Geophys. Res., 115, D00H19, doi:10.1029/2009JD012147.

— , and Coauthors, 2013: Four-dimensional distribution of the 2010 Eyjafjallajökull volcanic cloud over Europe observed by EARLINET. Atmos. Chem. Phys., 13, 4429-4450, doi:10.5194/ acp-13-4429-2013. 
Piringer, M., and Coauthors, 2007: The surface energy balance and the mixing height in urban areas-Activities and recommendations of COST-Action 715. Bound.-Layer Meteor., 124, 3 24, doi:10.1007/s10546-007-9170-0.

Pospichal, B., 2009: Diurnal to annual variability of the atmospheric boundary layer over West Africa: A comprehensive view by remote sensing observations. Doctoral thesis, Faculty of Mathematics and Natural Sciences, University of Cologne, 120 pp. [Available online at http://kups.ub.uni-koeln.de/2985/ 1/dissertation_pospichal.pdf.]

Pougatchev, N., G. Bingham, D. Seidel, and F. Berger, 2007: Statistical approach to validation of satellite atmospheric retrievals. Remote Sensing of Clouds and the Atmosphere XII, A. Comerón et al., Eds., International Society for Optical Engineering (SPIE Proceedings, Vol. 6745), doi:10.1117/12.737943.

Protat, A., and Coauthors, 2009: Assessment of Cloudsat reflectivity measurements and ice cloud properties using ground-based and airborne cloud radar observations. J. Atmos. Oceanic Technol., 26, 1717-1741, doi:10.1175/2009JTECHA1246.1.

— J. Delanoë, E. J. O'Connor, and T. S. L'Ecuyer, 2010: The evaluation of CloudSat and CALIPSO ice microphysical products using ground-based cloud radar and lidar observations. J. Atmos. Oceanic Technol., 27, 793-810, doi:10.1175/2009JTECHA1397.1.

_ D. Bouniol, E. J. O'Connor, H. K. Baltink, J. Verlinde, and K. Widener, 2011: Cloudsat as a global radar calibrator. J. Atmos. Oceanic Technol., 28, 445-452, doi:10.1175/2010JTECHA1443.1.

Ricaud, P., B. Gabard, S. Derrien, J. L. Attié, T. Rose, and H. Czekala, 2010: Validation of tropospheric water vapor as measured by the 183-GHz HAMSTRAD radiometer over the Pyrenees Mountains, France. IEEE Trans. Geosci. Remote Sens., 48, 2189-2203, doi:10.1109/TGRS.2009.2037920.

Roebeling, R. A., A. J. Feijt, and P. Stammes, 2006: Cloud property retrievals for climate monitoring: Implications of differences between Spinning Enhanced Visible and Infrared Imager (SEVIRI) on METEOSAT-8 and Advanced Very High Resolution Radiometer (AVHRR) on NOAA-17. J. Geophys. Res., 111, D20210, doi:10.1029/2005JD006990.

Roelofs, G.-J., H. ten Brink, A. Kiendler-Scharr, G. de Leeuw, A. Mensah, A. Minikin, and R. Otjes, 2010: Evaluation of simulated aerosol properties with the aerosol-climate model ECHAM5-HAM using observations from the IMPACT field campaign. Atmos. Chem. Phys., 10, 7709-7722, doi:10.5194/ acp-10-7709-2010.

Rose, T., S. Crewell, U. Löhnert, and C. Simmer, 2005: A network suitable microwave radiometer for operational monitoring of the cloudy atmosphere. Atmos. Res., 75, 183-200, doi:10.1016/ j.atmosres.2004.12.005.

Rosoldi, M., and Coauthors, 2013: Study of thin clouds at CNRIMAA Atmospheric Observatory (CIAO). Ann. Geophys., 56, doi:10.4401/ag-6337.

Sawamura, P., and Coauthors, 2012: Stratospheric AOD after the 2011 eruption of Nabro volcano measured by lidars over the Northern Hemisphere. Environ. Res. Lett., 7, 034013, doi:10.1088/ 1748-9326/7/3/034013.

Seibert, P., F. Beyrich, S. Gryning, S. Joffre, A. Rasmussen, and P. Tercier, 2000: Review and intercomparison of operational methods for the determination of the mixing height. Atmos. Environ., 34, 1001-1027, doi:10.1016/S1352-2310(99)00349-0.

Shupe, M. D., J. M. Comstock, D. D. Turner, and G. G. Mace, 2016: Cloud property retrievals in the ARM Program. The Atmospheric Radiation Measurement (ARM) Program: The First 20 Years, Meteor. Monogr., No. 57, Amer. Meteor. Soc., doi:10.1175/ AMSMONOGRAPHS-D-15-0030.1.
Spänkuch, D., W. Döhler, J. Güldner, and A. Keens, 1996: Ground-based passive atmospheric remote sounding by FTIR emission spectroscopy: First results with EISAR. Atmos. Phys, 69, 97-111.

Stegehuis, A. I., R. Vautard, P. Ciais, A. J. Teuling, M. Jung, and P. Yiou, 2013: Summer temperatures in Europe and land heat fluxes in observation-based data and regional climate model simulations. Climate Dyn., 41, 455-477, doi:10.1007/s00382-012-1559-x.

Stokes, G. M., 2016: Original ARM concept and launch. The Atmospheric Radiation Measurement (ARM) Program: The First 20 Years, Meteor. Monogr., No. 57, Amer. Meteor. Soc., doi:10.1175/AMSMONOGRAPHS-D-15-0021.1.

Tonttila, J., E. J. O'Connor, S. Niemela, P. Raisanen, and H. Jarvinen, 2011: Cloud base vertical velocity statistics: A comparison between an atmospheric mesoscale model and remote sensing observations. Atmos. Chem. Phys., 11, 9207-9218, doi:10.5194/acp-11-9207-2011.

Turner, D. D., and E. J. Mlawer, 2010: The Radiative Heating in Underexplored Bands Campaigns. Bull. Amer. Meteor. Soc., 91, 911-923, doi:10.1175/2010BAMS2904.1.

_, and U. Löhnert, 2014: Information content and uncertainties in thermodynamic profiles and liquid cloud properties retrieved from the ground-based Atmospheric Emitted Radiance Interferometer (AERI). J. Appl. Meteor. Climatol., 53, 752-771, doi:10.1175/JAMC-D-13-0126.1.

, M. P. Caddedu, U. Löhnert, S. Crewell, and A. M. Vogelmann, 2009: Modifications to the water vapor continuum in the microwave suggested by ground-based $150 \mathrm{GHz}$ Observations. IEEE Trans. Geosci. Remote Sens., 47, 33263337, doi:10.1109/TGRS.2009.2022262.

_, and Coauthors, 2012: Ground-based high spectral resolution observations of the entire terrestrial spectrum under extremely dry conditions. Geophys. Res. Lett., 39, L10801, doi:10.1029/2012GL051542.

van Meijgaard, E., and S. Crewell, 2005: Comparison of model predicted liquid water path with ground-based measurements during CLIWA-NET. Atmos. Res., 75, 201-226, doi:10.1016/ j.atmosres.2004.12.006.

van Zadelhoff, G. J., D. P. Donovan, H. K. Baltink, and R. Boers, 2004: Comparing ice cloud microphysical properties using Cloudnet and Atmospheric Radiation Measurement Program data. J. Geophys. Res., 109, D24214, doi:10.1029/2004JD004967.

Veselovskii, I., A. Kolgotin, V. Griaznov, D. Müller, U. Wandinger, and D. Whiteman, 2002: Inversion with regularization for the retrieval of tropospheric aerosol parameters from multiwavelength lidar sounding. Appl. Opt., 41, 3685-3699, doi:10.1364/AO.41.003685.

Villani, M. G., and Coauthors, 2006: Transport of volcanic aerosol in the troposphere: the case study of the 2002 Etna plume. J. Geophys. Res., 111, D21102, doi:10.1029/2006JD007126.

Wagner, J., A. Ansmann, U. Wandinger, P. Seifert, A. Schwarz, M. Tesche, A. Chaikovsky, and O. Dubovik, 2013: Evaluation of the Lidar/Radiometer Inversion Code (LIRIC) to determine microphysical properties of volcanic and desert dust. Atmos. Meas. Tech., 6, 1707-1724, doi:10.5194/amt-6-1707-2013.

Wang, P., and Coauthors, 2011: Cloudy sky shortwave radiative closure for a Baseline Surface Radiation Network site. J. Geophys. Res., 116, D08202, doi:10.1029/2010JD015141.

Westbrook, C. D., and A. J. Illingworth, 2009: Testing the influence of small crystals on ice size spectra using Doppler lidar observations. Geophys. Res. Lett., 36, L12810, doi:10.1029/2009GL038186. , and - 2011: Evidence that ice forms primarily in supercooled liquid clouds at temperatures $>-27^{\circ} \mathrm{C}$. Geophys. Res. Lett., 38, L14808, doi:10.1029/2011GL048021. 
and -2013 : The formation of ice in a long-lived supercooled layer cloud. Quart. J. Roy. Meteor. Soc., 139, 22092221, doi:10.1002/qj.2096.

, — — E. J. O'Connor, and R. J. Hogan, 2010: Doppler lidar measurements of oriented planar ice crystals falling from supercooled and glaciated layer clouds. Quart. J. Roy. Meteor. Soc., 136, 260-276, doi:10.1002/qj.528.

Westwater, E. R., S. Crewell, C. Mätzler, and D. Cimini, 2005: Principles of surface-based microwave and millimeter wave radiometric remote sensing of the troposphere. Quad. Soc. Ital. Elettromagn., 1 (3), 50-90.

Wetzel, G., and Coauthors, 2013: Validation of MIPAS-ENVISAT H2O operational data collected between July 2002 and March 2004. Atmos. Chem. Phys., 13, 5791-5811, doi:10.5194/ acp-13-5791-2013.

Wiegner, M., and A. Geiß, 2012: Aerosol profiling with the Jenoptik ceilometer CHM15kx. Atmos. Meas. Tech., 5, 19531964, doi:10.5194/amt-5-1953-2012.

Wiegner, M. J., and Coauthors, 2008: Numerical simulations of optical properties of Saharan dust aerosols with special emphasis on the linear depolarization ratio. Tellus, 61B, 180-194, doi:10.1111/j.1600-0889.2008.00381.x.
Wiegner, M., and Coauthors, 2014: What is the benefit of ceilometers for aerosol remote sensing? An answer from EARLINET. Atmos. Meas. Tech., 7, 1979-1997, doi:10.5194/amt-7-1979-2014.

Willen, U., S. Crewell, H. K. Baltink, and O. Sievers, 2005: Assessing model predicted vertical cloud structure and cloud overlap with radar and lidar ceilometer observations for the Baltex Bridge Campaign of CLIWA-NET. Atmos. Res., 75, 227-255, doi:10.1016/j.atmosres.2004.12.008.

Wulfmeyer, V., and Coauthors, 2011: The Convective and Orographically Induced Precipitation Study (COPS): The scientific strategy, the field phase, and research highlights. Quart. J. Roy. Meteor. Soc., 137, 3-30, doi:10.1002/qj.752.

Xie, S., and Coauthors, 2010: Clouds and more: ARM climate modeling best estimate data: A new data product for climate studies. Bull. Amer. Meteor. Soc., 91, 13-20, doi:10.1175/ 2009BAMS2891.1.

Zhang, Q. J., and Coauthors, 2013: Formation of organic aerosol in the Paris region during the MEGAPOLI summer campaign: Evaluation of the volatility-basis-set approach within the CHIMERE model. Atmos. Chem. Phys., 13, 5767-5790, doi:10.5194/acp-13-5767-2013. 